\title{
Calculation of simultaneous chemical and phase equilibrium by the methodof Lagrange multipliers
}

\author{
Tsanas, Christos ; Stenby, Erling Halfdan; Yan, Wei
}

Published in:

Chemical Engineering Science

Link to article, DOI:

10.1016/j.ces.2017.08.033

Publication date:

2017

Document Version

Peer reviewed version

Link back to DTU Orbit

Citation (APA):

Tsanas, C., Stenby, E. H., \& Yan, W. (2017). Calculation of simultaneous chemical and phase equilibrium by the methodof Lagrange multipliers. Chemical Engineering Science, 174, 112-126.

https://doi.org/10.1016/j.ces.2017.08.033

\section{General rights}

Copyright and moral rights for the publications made accessible in the public portal are retained by the authors and/or other copyright owners and it is a condition of accessing publications that users recognise and abide by the legal requirements associated with these rights.

- Users may download and print one copy of any publication from the public portal for the purpose of private study or research.

- You may not further distribute the material or use it for any profit-making activity or commercial gain

- You may freely distribute the URL identifying the publication in the public portal

If you believe that this document breaches copyright please contact us providing details, and we will remove access to the work immediately and investigate your claim 


\section{Accepted Manuscript}

Calculation of Simultaneous Chemical and Phase Equilibrium by the Method of Lagrange Multipliers

Christos Tsanas, Erling H. Stenby, Wei Yan

PII:

S0009-2509(17)30547-X

DOI: http://dx.doi.org/10.1016/j.ces.2017.08.033

Reference: CES 13776

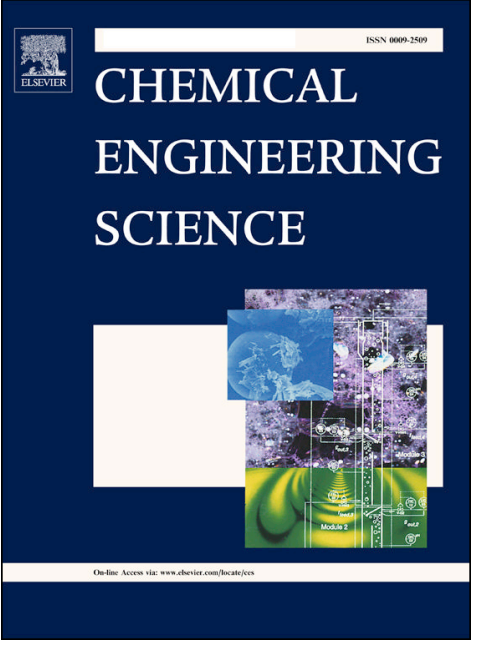

To appear in: $\quad$ Chemical Engineering Science

Received Date: $\quad 10$ January 2017

Accepted Date: $\quad 30$ August 2017

Please cite this article as: C. Tsanas, E.H. Stenby, W. Yan, Calculation of Simultaneous Chemical and Phase Equilibrium by the Method of Lagrange Multipliers, Chemical Engineering Science (2017), doi: http://dx.doi.org/ 10.1016/j.ces.2017.08.033

This is a PDF file of an unedited manuscript that has been accepted for publication. As a service to our customers we are providing this early version of the manuscript. The manuscript will undergo copyediting, typesetting, and review of the resulting proof before it is published in its final form. Please note that during the production process errors may be discovered which could affect the content, and all legal disclaimers that apply to the journal pertain. 


\title{
Calculation of Simultaneous Chemical and Phase Equilibrium by the Method of Lagrange Multipliers
}

\author{
Christos Tsanas, Erling H. Stenby, Wei Yan*
}

Center for Energy Resources Engineering (CERE), Department of Chemistry, Technical University of Denmark, 2800 Kongens Lyngby, Denmark

\begin{abstract}
The purpose of this work is to develop a general, reliable and efficient algorithm, which is able to deal with multiple reactions in multiphase systems. We selected the method of Lagrange multipliers to minimize the Gibbs energy of the system, under material balance constraints. Lagrange multipliers and phase amounts are the independent variables, whose initialization is performed by solving a subset of the working equations. This initialization is the unconstrained minimization of a convex function and it is bound to converge. The whole solution procedure employs a nested loop with Newton iteration in the inner loop and non-ideality updated in the outer loop, thus giving an overall linear convergence rate. Stability analysis is used to introduce additional phases sequentially so as to obtain the final multiphase solution. The procedure was successfully tested on vapor-liquid equilibrium (VLE) and vapor-liquid-liquid equilibrium (VLLE) of reaction systems.

Keywords: algorithm, chemical equilibrium, phase equilibrium, heterogeneous synthesis
\end{abstract}

\section{Introduction}

Simultaneous chemical and phase equilibrium (CPE) calculations are vital for chemical engineering research and simulations. Even when a process can-

\footnotetext{
* Corresponding author

Email address: weya@kemi.dtu.dk (Wei Yan)
}

Preprint submitted to Chemical Engineering Science

July 23, 2017 
not reach equilibrium conditions due to kinetic obstructions, CPE calculations provide a thermodynamic limit as reference. Such calculations usually apply in reactive distillation, where the reactions allow separation of desired products or isomers, as well as elimination of azeotropes. Moreover, CPE calculations are needed in heterogeneous organic synthesis, when there are more than one reaction phases. Other applications include weak electrolyte equilibrium in geochemistry and fuels/chemicals from renewable feedstocks.

q One of the oldest algorithms for CPE calculations was published by Brinkley (1947), using a nested-loop scheme. Activity coefficients are constant in the inner loop and updated in the outer loop. White et al. (1958) developed an efficient algorithm for ideal mixtures, known as the RAND algorithm, which 15 was generalized for non-ideal multiphase systems by Greiner (1991). Smith and Missen (1982) made a systematic categorization of CPE calculation procedures. According to them, there are two main categories: simultaneous solution of equilibrium equations and Gibbs energy minimization. The second category includes stoichiometric and non-stoichiometric methods, minimizing the Gibbs energy with respect to extents of reactions and using Lagrange multipliers respectively.

घ The non-stoichiometric problem was thoroughly explained by Zeleznik and Gordon (1968), along with perturbation calculations to initialize computations for challenging systems. Gautam and Wareck (1986) provide a complete set

25 of different reactive flash specifications. Gautam and Seider (1979a b c), and White and Seider (1981) published a detailed description of CPE and additional aspects, such as stability analysis or inclusion of electrolytes. Michelsen (1989) introduced an algorithm for ideal mixtures, suggesting implementation of successive substitution in a nested-loop procedure for non-ideal mixtures. Phoenix 30 and Heidemann (1998) developed a stoichiometric and a non-stoichiometric algorithm, starting with a number of phases and combining those of same composition and density during convergence. Barbosa and Doherty (1988), and Ung and Doherty (1995a b c d e), studied reaction systems, identifying reactive azeotropes and presented a set of transformed composition variables, widely 
used by a number of authors in later publications. Pérez Cisneros et al. (1997), with different transformations from those of Barbosa, Doherty and Ung, stressed the dependence of solutions on model parameters.

McDonald and Floudas (1995, 1997), and Floudas and Visweswaran (1990) worked on global optimization methods. Jalali-Farahani and Seader (2000), and

40 Jalali et al. (2008) implemented the homotopy continuation method, mentioning its potential to find all the solutions. Wasylkiewicz and Ung (2000) suggested a method to track all stationary points of the Gibbs energy minimization. BonillaPetriciolet et al. (2006, 2011), and Bonilla-Petriciolet and Segovia-Hernández (2010) focused on global optimization using stochastic methods, such as simu-

45 lated annealing or the firefly algorithm. An alternative approach was presented by Moodley et al. (2015), where the stochastic method simulates the herding behavior of the krill crustacean.

In our work, we have extended the method presented by Michelsen (1989) to non-ideal mixtures and extensively applied it to phase equilibrium of reaction systems. A similar description is outlined in Michelsen and Mollerup (2007) for a single-phase system. Overall, it is a non-stoichiometric algorithm with Lagrange multipliers and phase amounts as independent variables. The minimization equations are solved with Newton's method. Proper initialization of the variables has proven to overcome the problem of divergence. First, one-phase system is assumed and the algorithm is implemented until full convergence. Stability analysis is subsequently utilized to judge, if the addition of a new phase is necessary. The set of phases that is deemed stable, is the final solution. The method was applied to ideal and non-ideal vapor-liquid equilibrium (VLE) and vapor-liquid-liquid equilibrium (VLLE) of reaction systems. Possible applications of interest include heterogeneous organic synthesis and separation, where it is sought to optimize the yields of desired products. 


\section{Method}

\subsection{Minimization of Gibbs energy}

A multiphase reaction system is at equilibrium, when, under constant temperature and pressure, the Gibbs energy attains its global minimum. Mole numbers of components must satisfy two types of constraints:

- material balance: mass is conserved

- non-negativity: only non-negative mole numbers have physical meaning

Due to chemical reactions, system components are not independent. Provided that there are no additional stoichiometric constraints and we choose a set of linearly independent reactions, the Gibbs phase rule has the form (Rao, 1985):

$$
F=N_{C}-N_{R}-N_{P}+2
$$

where $F$ is the number of degrees of freedom, $N_{C}$ the number of components, $N_{R}$ the number of linearly independent chemical reactions and $N_{P}$ the number 75 of phases. As a result, $N_{E}=N_{C}-N_{R}$ independent entities have to be defined as a basis to describe the system. These entities are called elements and they can be single chemical elements or groups of atoms. The material balance in reaction systems is expressed in terms of elements. Isomers, although share the same chemical composition, must be "composed" by separate elements.

Gibbs energy constrained minimization is concisely formulated as:

$$
\begin{array}{ll} 
& \min _{\mathbf{n}} G(T, p, \mathbf{n})=\min _{n_{i k}} \sum_{k=1}^{N_{P}} \sum_{i=1}^{N_{C}} n_{i k} \mu_{i k}\left(T, p, \mathbf{n}_{k}\right) \\
\text { s.t. } & \sum_{k=1}^{N_{P}} \sum_{i=1}^{N_{C}} A_{j i} n_{i k}=b_{j}, \quad j=1, \ldots, N_{E} \\
& n_{i k} \geq 0, \quad i=1, \ldots, N_{C} \quad k=1, \ldots, N_{P}
\end{array}
$$

where $G$ is the Gibbs energy, $T$ the temperature, $p$ the pressure, $n_{i k}$ and $\mu_{i k}$ the mole numbers and chemical potential of component $i$ in phase $k, \mathbf{n}_{k}$ the 
components abundance vector in phase $k, A_{j i}$ the number of element $j$ in component $i$ and $b_{j}$ the total mole numbers of element $j$. The material balance in 85 the matrix-vector form is:

$$
\mathbf{A} \sum_{k=1}^{N_{P}} \mathbf{n}_{k}=\mathbf{b}
$$

where $\mathbf{A}$ is the formula matrix and $\mathbf{b}$ the element abundance vector. The latter can be found from the single-phase feed mole numbers, $\mathbf{n}_{F}$ :

$$
\mathbf{b}=\mathbf{A} \mathbf{n}_{F}
$$

Chemical potential is calculated from:

$$
\mu_{i k}=\mu_{i k}^{\circ}+R T \ln \frac{\hat{f}_{i k}}{f_{i k}^{\circ}}
$$

where $\mu_{i k}^{\circ}$ is the reference state chemical potential of component $i$ in phase $k$,

90 $R$ the gas constant, $\hat{f}_{i k}$ the fugacity of component $i$ in phase $k$ and $f_{i k}^{\circ}$ the reference state fugacity of component $i$ in phase $k$.

If the same EoS is used for all phases, the ideal gas reference state is selected at the temperature of the system: $\mu_{i k}^{\circ}=\mu_{i}^{*}\left(T, p^{*}\right)$ and $f_{i k}^{\circ}=p^{*}$, where $p^{*}$ is usually $1 \mathrm{~atm}$ or 1 bar. If an activity coefficient model is used for liquid phases,

${ }_{95}$ the pure component reference state is selected for those phases at the temperature and pressure of the system: $\mu_{i k}^{\circ}=\mu_{i k}^{\text {pure }}(T, p)$ and $f_{i k}^{\circ}=f_{i k}(T, p)$. The subscript $k$ is used in $f_{i k}$ only to differentiate vapor and liquid pure component fugacities. It is possible to change between the two reference states:

$$
\mu_{i}^{*}-\mu_{i k}^{\text {pure }}=R T \ln \frac{p^{*}}{f_{i k}}
$$

Fugacities are calculated from an EoS by:

$$
\hat{f}_{i k}=x_{i k} \hat{\phi}_{i k} p
$$

100

where $x_{i k}$ is the mole fraction of component $i$ in phase $k$ and $\hat{\phi}_{i k}$ the fugacity coefficient of component $i$ in phase $k$. For a liquid phase described by an activity 
coefficient model, fugacities are calculated by:

$$
\hat{f}_{i k}=x_{i k} \gamma_{i k} f_{i k}
$$

where $\gamma_{i k}$ is the activity coefficient of component $i$ in liquid phase $k$. An equivalent fugacity coefficient is given by:

$$
\hat{\phi}_{i k}=\frac{\gamma_{i k} f_{i k}}{p}
$$

At low pressures, for a liquid:

$$
f_{i k}=p_{i}^{s}
$$

where $p_{i}^{s}$ is the vapor pressure of component $i$. It must be clarified that ideal vapor phases behave like ideal gases $(\hat{\phi}=1)$, while ideal liquid phases behave like ideal solutions $(\gamma=1)$.

Reactions between components $\mathcal{A}_{i}$ can be expressed as:

$$
\sum_{i=1}^{N_{C}} \mathcal{A}_{i} \nu_{i r}=0, \quad r=1, \ldots, N_{R}
$$

where $\nu_{i r}$ is the stoichiometric coefficient of component $i$ in reaction $r$, positive for products and negative for reactants. With stoichiometric coefficients as its entries, the stoichiometric matrix $\mathbf{N}$ is a complete representation of all the reactions. The product of the formula matrix with the stoichiometric matrix must satisfy:

$$
\mathbf{A N}=\mathbf{0}
$$

Temperature is constant, hence the Gibbs energy has the same minimum as the reduced Gibbs energy, $G /(R T)$. The Lagrangian of the latter is:

$$
\mathcal{L}(\mathbf{n}, \boldsymbol{\lambda})=\sum_{k=1}^{N_{P}} \sum_{i=1}^{N_{C}} \frac{n_{i k} \mu_{i k}}{R T}-\sum_{j=1}^{N_{E}} \lambda_{j}\left(\sum_{k=1}^{N_{P}} \sum_{i=1}^{N_{C}} A_{j i} n_{i k}-b_{j}\right)
$$


where $\lambda_{j}$ is the Lagrange multiplier of element $j$. The solution is a stationary point of the Lagrangian, satisfying:

$$
\begin{gathered}
\frac{\partial \mathcal{L}}{\partial n_{i k}}=\frac{\mu_{i k}}{R T}-\sum_{j=1}^{N_{E}} A_{j i} \lambda_{j}=0, \quad i=1, \ldots, N_{C} \quad k=1, \ldots, N_{P} \\
\frac{\partial \mathcal{L}}{\partial \lambda_{j}}=-\sum_{k=1}^{N_{P}} \sum_{i=1}^{N_{C}} A_{j i} n_{i k}+b_{j}=0, \quad j=1, \ldots, N_{E}
\end{gathered}
$$

We must mention that this point is a saddle of the Lagrangian. The purpose is not to minimize the Lagrangian, but the reduced Gibbs energy. Instead of solving this set of equations, we introduce the mole fractions and the phase amounts in Eq. 15

$$
F_{j}^{A}=\sum_{k=1}^{N_{P}} n_{t, k} \sum_{i=1}^{N_{C}} A_{j i} x_{i k}-b_{j}=0, \quad j=1, \ldots, N_{E}
$$

Mole fractions in each phase must also satisfy:

$$
F_{k}^{B}=\sum_{i=1}^{N_{C}} x_{i k}-1=0, \quad k=1, \ldots, N_{P}
$$

From Eq. 5 and 14 , the mole fraction can be expressed as a function of the

Lagrange multipliers:

$$
\ln x_{i k}=\sum_{j=1}^{N_{E}} A_{j i} \lambda_{j}-\frac{\mu_{i k}^{\circ}}{R T}-\ln \frac{\hat{\phi}_{i k} p}{f_{i k}^{\circ}}
$$

The working equations of the procedure are given by Eq. 16 and 17 . The independent variables at equilibrium, $\boldsymbol{\lambda}$ and $\mathbf{n}_{t}$, are roots of the function $\mathbf{F}$ :

$$
\mathbf{F}\left(\boldsymbol{\lambda}, \mathbf{n}_{t}\right)=\left[\begin{array}{l}
\mathbf{F}^{A} \\
\mathbf{F}^{B}
\end{array}\right]
$$

To find the Jacobian of $\mathbf{F}$, derivatives of $x_{i k}$ are required. Whenever we use the Jacobian in calculations, we assume that the fugacity coefficients are constant. Therefore:

$$
\frac{\partial x_{i k}}{\partial \lambda_{q}}=A_{q i} x_{i k}, \quad q=1, \ldots, N_{E}
$$


and:

$$
\frac{\partial x_{i k}}{\partial n_{t, q}}=0, \quad q=1, \ldots, N_{P}
$$

Finally, the Jacobian matrix of function $\mathbf{F}$ has the form:

$$
\mathbf{J}\left(\boldsymbol{\lambda}, \mathbf{n}_{t}\right)=\left[\begin{array}{ll}
\mathbf{J}^{A} & \mathbf{J}^{B} \\
\mathbf{J}^{C} & \mathbf{J}^{D}
\end{array}\right]
$$

where:

$$
\begin{gathered}
J_{j q}^{A}=\frac{\partial F_{j}^{A}}{\partial \lambda_{q}}=\sum_{k=1}^{N_{P}} n_{t, k} \sum_{i=1}^{N_{C}} A_{j i} A_{q i} x_{i k}, \quad j=1, \ldots, N_{E} \quad q=1, \ldots, N_{E} \\
J_{j q}^{B}=\frac{\partial F_{j}^{A}}{\partial n_{t, q}}=\sum_{i=1}^{N_{C}} A_{j i} x_{i q}, \quad j=1, \ldots, N_{E} \quad q=1, \ldots, N_{P} \\
J_{k q}^{C}=\frac{\partial F_{k}^{B}}{\partial \lambda_{q}}=\sum_{i=1}^{N_{C}} A_{q i} x_{i k}=J_{q k}^{B}, \quad k=1, \ldots, N_{P} \quad q=1, \ldots, N_{E} \\
J_{k q}^{D}=\frac{\partial F_{k}^{B}}{\partial n_{t, q}}=0, \quad k=1, \ldots, N_{P} \quad q=1, \ldots, N_{P}
\end{gathered}
$$

or

$$
\mathbf{J}\left(\boldsymbol{\lambda}, \mathbf{n}_{t}\right)=\left[\begin{array}{cc}
\mathbf{J}^{A} & \mathbf{J}^{B} \\
\left(\mathbf{J}^{B}\right)^{\mathrm{T}} & \mathbf{0}
\end{array}\right]
$$

The solution of $\mathbf{F}$ is determined iteratively with the Newton's method:

$$
\mathbf{J}\left[\begin{array}{c}
\Delta \lambda \\
\Delta \mathbf{n}_{t}
\end{array}\right]=-\mathbf{F}
$$

A nested-loop scheme is employed: in the inner loop we keep constant the values of fugacity or activity coefficients. When the estimate of Eq. 28 converges, we update all non-ideality quantities in the outer loop. The dimensions of the system in the inner loop is $N_{E}+N_{P}$. The original working equations (Eq. 
140 nested-loop scheme uses $\left(N_{C}-1\right) N_{P}$ fewer variables. According to Eq. 14. a relationship can be found between the minimum Gibbs energy and the Lagrange multipliers:

$$
\begin{aligned}
\frac{G_{\min }}{R T} & =\sum_{k=1}^{N_{P}} \sum_{i=1}^{N_{C}} \frac{n_{i k} \mu_{i k}}{R T}=\sum_{k=1}^{N_{P}} \sum_{i=1}^{N_{C}} n_{i k} \sum_{j=1}^{N_{E}} A_{j i} \lambda_{j}= \\
& =\sum_{j=1}^{N_{E}} \lambda_{j} \sum_{k=1}^{N_{P}} \sum_{i=1}^{N_{C}} A_{j i} n_{i k}=\sum_{j=1}^{N_{E}} b_{j} \lambda_{j}
\end{aligned}
$$

Eq. 29 shows that the minimum Gibbs energy is a homogeneous function of degree one in the mole numbers of the elements $b_{j}$, therefore:

$$
\left(\frac{\partial G_{\min }}{\partial b_{j}}\right)_{T, p, b_{q \neq j}}=R T \lambda_{j}
$$

In other words, the Lagrange multipliers represent the reduced chemical potential of the elements at equilibrium.

\subsection{Initialization}

To initialize calculations, usually a linear programming problem is solved for non-zero mole numbers of $N_{E}$ components (Michelsen and Mollerup, 2007). From this solution we can determine estimates of $\boldsymbol{\lambda}$ and $\mathbf{n}_{t}$. Disadvantages associated with this method are, except degenerate cases, the poor estimation of small concentrations or the possibility that we find a solution with less than $N_{E}$ components present. In this case, there is not enough information to determine

${ }_{155} \boldsymbol{\lambda}$ (Michelsen and Mollerup, 2007).

To avoid solving this problem, we estimate the phase amounts and determine the Lagrange multipliers from an unconstrained minimization problem. In general, it is easier to decide on a reasonable estimate for $\mathbf{n}_{t}$ rather than $\boldsymbol{\lambda}$ at equilibrium. We assume that the mole numbers of a single phase will be between a minimum and a maximum value, due to reactions. In this work, the initial guess for $n_{t}$ was selected as the average of these two values. Although generalization for a multiphase system is not addressed here, initial estimates of 
phase amounts were found less critical for convergence. Once the phase amounts are initialized, they are kept constant and the following function is defined:

$$
Q(\boldsymbol{\lambda})=\sum_{k=1}^{N_{P}} n_{t, k}\left(\sum_{i=1}^{N_{C}} x_{i k}-1\right)-\sum_{j=1}^{N_{E}} \lambda_{j} b_{j}
$$

165

Lagrange multipliers. This involves the solution of:

$$
\nabla^{2} Q \Delta \boldsymbol{\lambda}=-\nabla Q
$$

or, according to Eq. 16 and 23 .

$$
\mathbf{J}^{A} \Delta \boldsymbol{\lambda}=-\mathbf{F}^{A}
$$

The matrix-vector form of Eq. 23 is:

$$
\mathbf{J}^{A}=\mathbf{A} \operatorname{diag}\left(\sum_{k=1}^{N_{P}} \mathbf{n}_{k}\right) \mathbf{A}^{\mathrm{T}}
$$

The entries of the diagonal matrix are the total mole numbers of each component, which are positive. Consequently, the diagonal matrix is positive definite. Since matrix $\mathbf{A}$ has full rank, matrix $\mathbf{J}^{A}$ is positive definite as well. Function $Q$ is convex and we will ultimately find its unique minimizer. The Lagrange multipliers we calculated and the phase amounts we guessed are initial estimates for the full Newton's method in Eq. 28.

175

\subsection{Stability analysis}

We must perform stability analysis to verify that no additional phase can lower the current Gibbs energy of the system. The method used was presented by Michelsen (1982) and later in Michelsen and Mollerup (2007): a phase with composition $\mathbf{z}$ is unstable when there is composition $\mathbf{w}$, for which the tangent

$$
T P D(\mathbf{w})=\sum_{i=1}^{N_{C}} w_{i}\left[\mu_{i}(\mathbf{w})-\mu_{i}(\mathbf{z})\right]<0
$$


Negative values of $T P D$ can be identified through determination of its minima (Michelsen, 1982) and a phase split occurs if a negative TPD is found during the search. Stability analysis for multiphase calculations is essentially the same as for a two-phase system. Any phase of the converged solution can be used to test the overall stability. However, special care needs to be taken for the initial estimates in multiphase calculation (Michelsen, 1982, Michelsen and Mollerup, 2007).

\subsection{Assignment of reference state chemical potential}

The reference state chemical potential is needed to calculate mole fractions from Eq. 18. It can be found in tables for specific $T$ and $p$. Although necessary, this information is not always available. Instead, chemical equilibrium constants are more frequently reported:

$$
K_{r k}^{\mathrm{eq}}=\exp \left(-\frac{\Delta_{r} G_{r k}^{\circ}}{R T}\right)=\exp \left(-\sum_{i=1}^{N_{C}} \frac{\nu_{i r} \mu_{i k}^{\circ}}{R T}\right)
$$

where $K_{r k}^{\mathrm{eq}}$ is the chemical equilibrium constant of reaction $r$ in phase $k$ and $\Delta_{r} G_{r k}^{\circ}$ the reference state Gibbs energy of reaction $r$ in phase $k$, which can also be calculated based on the Gibss energy of formation or Gibbs energy of combustion.

In total $N_{C}$ reference state chemical potentials are missing from phase $k$, but there are only $N_{R}$ chemical equilibrium constants. Absolute values of $\mu_{i k}^{\circ}$ do not matter for the calculations, as long as they satisfy Eq. 36. In place of the real reference state chemical potential, we "decompose" the chemical equilibrium constants into fictitious, yet consistent, values: $N_{R}$ reference components are selected, that participate in one reaction at least (no inerts) and we assign:

$$
\mu_{i k}^{\circ}= \begin{cases}\hat{\mu}_{i k}, & i \in \text { reference components } \\ 0, & i \notin \text { reference components }\end{cases}
$$


The following system is solved for $\hat{\boldsymbol{\mu}}_{k} /(R T)$ :

$$
\frac{1}{R T} \hat{\mathbf{N}}^{\mathrm{T}} \hat{\boldsymbol{\mu}}_{k}=\left[\begin{array}{c}
-\ln K_{1 k}^{\mathrm{eq}} \\
\cdot \\
\cdot \\
\cdot \\
-\ln K_{r k}^{\mathrm{eq}}
\end{array}\right]
$$

where $\hat{\mathbf{N}}$ is the stoichiometric matrix of the $N_{R}$ reference components we chose. When all phases share the same reference state, then $\mu_{i k}^{\circ}=\left.\mu_{i q}^{\circ}\right|_{q \neq k}$ for all components. Otherwise, Eq. 6 must be used.

\section{Results and discussion}

In this work, $Q$ function (Eq. 31) is minimized assuming a single ideal phase. Afterwards, stability analysis provides the necessary composition estimates, when an additional phase must be considered. Starting values for the Lagrange multipliers in the new phase set are taken from the previous solution and $n_{t, \text { new phase }}=0$. The procedure stops when the maximum error in the independent variables $\left(\boldsymbol{\lambda}\right.$ and $\left.\mathbf{n}_{t}\right)$ is less than $10^{-10}$. The error at iteration $q \geq 1$ is calculated as:

$$
\operatorname{error}^{(q)}=\sqrt{\sum_{j=1}^{N_{E}}\left[\lambda_{j}^{(q)}-\lambda_{j}^{(q-1)}\right]^{2}+\sum_{k=1}^{N_{P}}\left[n_{t, k}^{(q)}-n_{t, k}^{(q-1)}\right]^{2}}
$$

Figure 11 summarizes the suggested procedure for solving CPE involving multiple phases and multiple reactions. It should be noted that this method is intended to provide a general and safe solution. Therefore, calculations start from a single phase and additional phases are introduced in a step-wise manner, one at a time. It is possible to start calculations from more than one phases. Although more risky, this might save time in actual calculation. Our trials have shown that the algorithm converges for most tested cases, even if initially $N_{P}>1$. Nevertheless, this is not the focus of this work. 
Table 1: Component and element numbering for the systems examined.

\begin{tabular}{|c|c|c|c|c|c|c|c|}
\hline System & & 1 & 2 & 3 & 4 & 5 & 7 \\
\hline $\begin{array}{c}\text { Formaldehyde/ } \\
\text { water }\end{array}$ & $\begin{array}{l}\text { Component } \\
\text { Element }\end{array}$ & $\begin{array}{l}\text { Formaldehyde } \\
\qquad \mathrm{CH}_{2} \mathrm{O}\end{array}$ & $\begin{array}{c}\text { Water } \\
\mathrm{H}_{2} \mathrm{O}\end{array}$ & Methylene glycol & Oxydimethanol & & \\
\hline $\begin{array}{c}\text { Xylene } \\
\text { separation }\end{array}$ & $\begin{array}{l}\text { Component } \\
\text { Element }\end{array}$ & $\begin{array}{l}\text { Di-tert-butylbenzene } \\
\qquad \mathrm{C}_{6} \mathrm{H}_{6}\end{array}$ & $\begin{array}{c}m \text {-Xylene } \\
\mathrm{C}_{4} \mathrm{H}_{8}\end{array}$ & $\begin{array}{c}\text { tert-Butyl- } m \text {-xylene } \\
\mathrm{C}_{8} \mathrm{H}_{10}\end{array}$ & $\begin{array}{l}\text { tert-Butylbenzene } \\
\mathrm{C}_{8} \mathrm{H}_{10} \text { (inert) }\end{array}$ & Benzene & $p$-Xylene \\
\hline $\begin{array}{l}\text { MTBE } \\
\text { synthesis }\end{array}$ & $\begin{array}{l}\text { Component } \\
\text { Element }\end{array}$ & $\begin{array}{c}\text { Isobutene } \\
\mathrm{C}_{4} \mathrm{H}_{8}\end{array}$ & $\begin{array}{c}\text { Methanol } \\
\mathrm{CH}_{4} \mathrm{O}\end{array}$ & $\begin{array}{c}n \text {-Butane } \\
\mathrm{C}_{4} \mathrm{H}_{10} \text { (inert) }\end{array}$ & MTBE & & \\
\hline $\begin{array}{c}\text { Acetic acid/ethanol } \\
\text { esterification }\end{array}$ & $\begin{array}{l}\text { Component } \\
\text { Element }\end{array}$ & $\begin{array}{c}\text { Acetic acid } \\
\mathrm{C}_{2} \mathrm{H}_{2} \mathrm{O}\end{array}$ & $\begin{array}{l}\text { Ethanol } \\
\mathrm{C}_{2} \mathrm{H}_{6} \mathrm{O}\end{array}$ & $\begin{array}{c}\text { Water } \\
\mathrm{H}_{2} \mathrm{O}\end{array}$ & Ethyl acetate & & \\
\hline $\begin{array}{l}\text { Cyclohexane } \\
\text { synthesis }\end{array}$ & $\begin{array}{l}\text { Component } \\
\text { Element }\end{array}$ & $\begin{array}{c}\text { Benzene } \\
\mathrm{C}_{6} \mathrm{H}_{6}\end{array}$ & $\begin{array}{c}\text { Hydrogen } \\
\mathrm{H}_{2}\end{array}$ & Cyclohexane & & & \\
\hline $\begin{array}{l}\text { Methanol } \\
\text { synthesis }\end{array}$ & $\begin{array}{c}\text { Component } \\
\text { Element }\end{array}$ & $\begin{array}{c}\text { Carbon monoxide } \\
\text { CO }\end{array}$ & $\begin{array}{c}\text { Carbon dioxide } \\
0\end{array}$ & $\begin{array}{c}\text { Hydrogen } \\
\mathrm{H}_{2}\end{array}$ & $\begin{array}{c}\text { Water } \\
\mathrm{CH}_{4} \text { (inert) }\end{array}$ & $\begin{array}{l}\text { Methanol } \\
\mathrm{C}_{18} \mathrm{H}_{38} \text { (inert) }\end{array}$ & Methane Octadecane \\
\hline
\end{tabular}

For simplicity, components and elements are numbered in each mixture. Table 1 illustrates the identity of components and the chemical composition of elements in the systems included in this work. Results reported are mole fractions $x_{i k}$, phase amounts $n_{t, k}$ and phase fractions $\beta_{k}$, given by:

$$
\beta_{k}=\frac{n_{t, k}}{\sum_{q=1}^{N_{P}} n_{t, q}}
$$

The main CPE solver as well as thermodynamic routines were all coded in FORTRAN using the compiler from Intel@ Parallel Studio XE 2015. In the current implementation we use functions provided by Intel@ MKL libraries (LAPACK). Function DSYTRF to factorize a symmetric matrix (LDL decomposition) and DSYTRS to solve the system. Other Cholesky decomposition routines have similar performance. EoS or activity coefficient models are implemented in a modular way, to avoid making the problem "fugacity-expression" dependent. The input of the routines is temperature, pressure and component mole numbers of a phase to obtain: from an activity coefficient model directly the activity coeffiients and from an EoS, after solving numercally for volume, the fugacity coefficients.

\subsection{System based on the chemistry of formaldehyde/water}

Maurer (1986) presented a set of reactions occuring in aqueous solutions

of formaldehyde. Here, similar to Ung and Doherty (1995e), only formation 


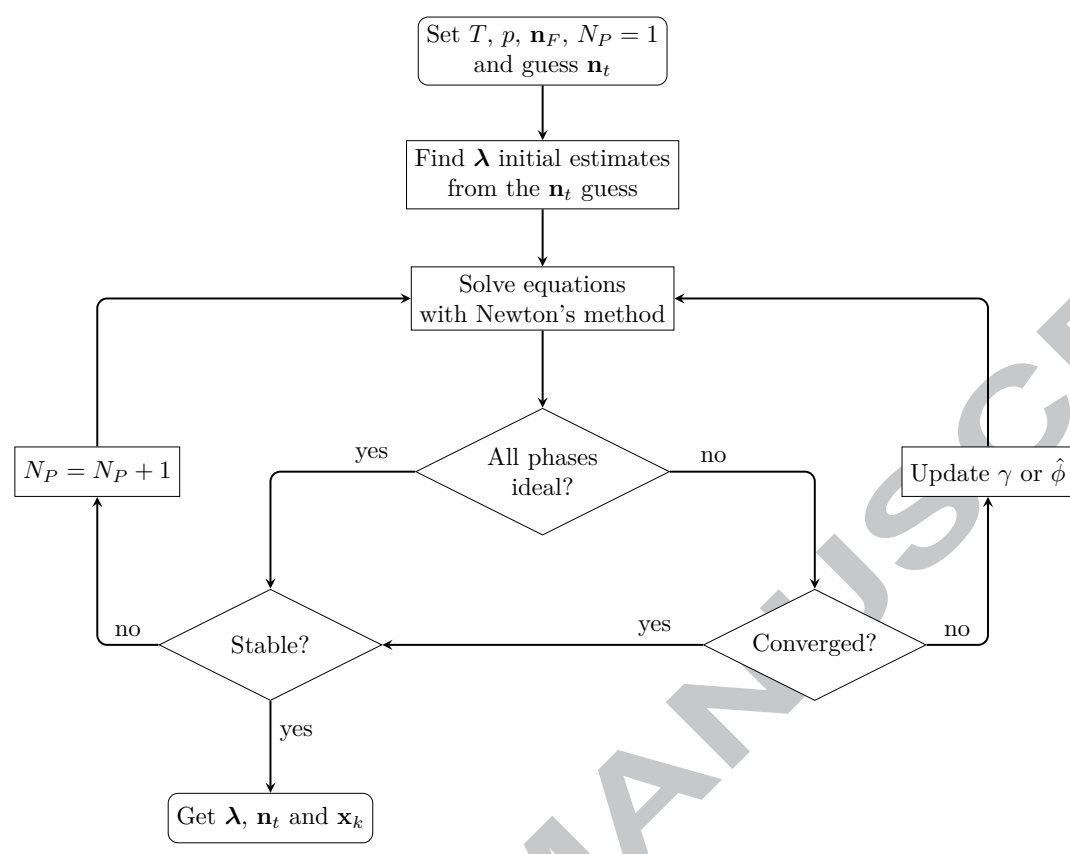

Figure 1: Flowchart of the reported algorithm.

of methylene glycol and oxydimethanol (dimer in polyoxymethylene polymerization) are considered for the calculations. Formaldehyde reacts with water to produce methylene glycol, which subsequently produces oxydimethanol in a condensation dimerization:

$$
\begin{gathered}
\mathrm{CH}_{2} \mathrm{O}+\mathrm{H}_{2} \mathrm{O} \rightleftharpoons \mathrm{CH}_{4} \mathrm{O}_{2} \\
2 \mathrm{CH}_{4} \mathrm{O}_{2} \rightleftharpoons \mathrm{C}_{2} \mathrm{H}_{6} \mathrm{O}_{3}+\mathrm{H}_{2} \mathrm{O}
\end{gathered}
$$

245. The number of elements is $N_{E}=N_{C}-N_{R}=4-2=2$. The formula matrix and stoichiometric matrix of the system are given by:

$$
\mathbf{A}=\left[\begin{array}{llll}
1 & 0 & 1 & 2 \\
0 & 1 & 1 & 1
\end{array}\right] \quad \mathbf{N}=\left[\begin{array}{cccc}
-1 & -1 & 1 & 0 \\
0 & 1 & -2 & 1
\end{array}\right]^{\mathrm{T}}
$$

Vapor and liquid phases are considered ideal as in Ung and Doherty (1995e), unlike in Maurer (1986), who used the UNIFAC activity coefficient model (Fre- 
denslund et al., 1975) for the liquid phase. Chemical equilibrium constants and advantage of the following reactions:

$$
\begin{aligned}
& \mathrm{C}_{14} \mathrm{H}_{22}+m-\mathrm{C}_{8} \mathrm{H}_{10} \rightleftharpoons \mathrm{C}_{12} \mathrm{H}_{18}+\mathrm{C}_{10} \mathrm{H}_{14} \\
& \mathrm{C}_{10} \mathrm{H}_{14}+m-\mathrm{C}_{8} \mathrm{H}_{10} \rightleftharpoons \mathrm{C}_{12} \mathrm{H}_{18}+\mathrm{C}_{6} \mathrm{H}_{6}
\end{aligned}
$$

where di-tert-butylbenzene reacts with $m$-xylene to produce tert-butyl- $m$-xylene and tert-butylbenzene, the latter reacting at the same time with $m$-xylene to produce tert-butyl- $m$-xylene and benzene. In this reaction system, $p$-xylene is 270 an inert. The number of elements is $N_{E}=N_{C}-N_{R}=6-2=4$. The formula 


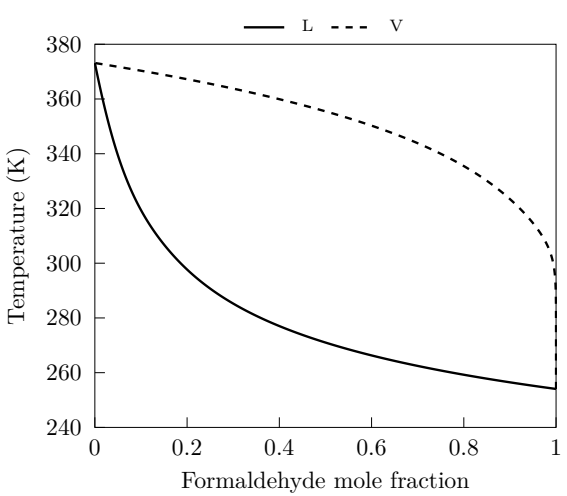

(a)

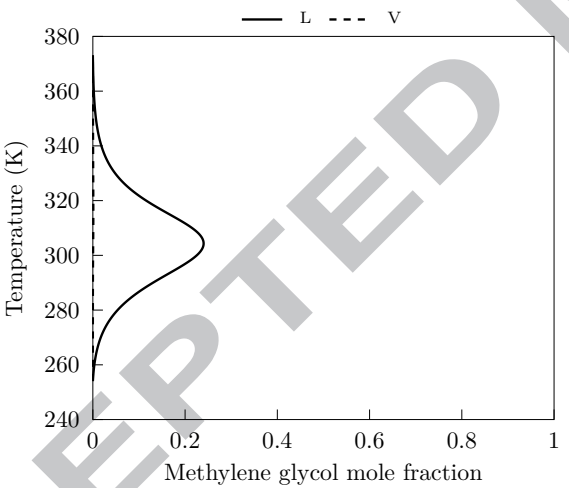

(c)

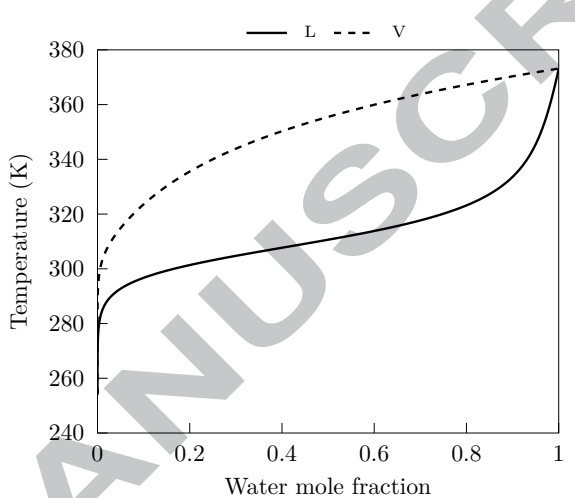

(b)

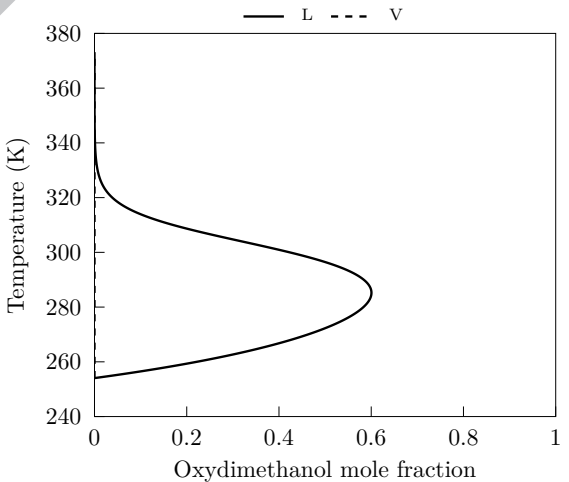

(d)

Figure 2: Equilibrium $T-y-x$ diagrams for formaldehyde (a), water (b), methylene glycol (c) and oxydimethanol (d) at $1 \mathrm{~atm}$. 
Table 2: Mole fractions in xylene separation at the bubble point of $44 \mathrm{mmHg}$.

\begin{tabular}{|c|c|c|c|c|c|c|}
\hline \multirow[t]{2}{*}{ Component } & \multirow[t]{2}{*}{ Feed } & \multicolumn{2}{|c|}{ Our work $-336.54 \mathrm{~K}$} & Saito et al. & $(1971)$ & $-331.15 \mathrm{~K}$ \\
\hline & & Vapor & Liquid & & Vapor & \\
\hline Di-tert-butylbenzene & 0.29 & 0.01 & 0.29 & & 0.02 & \\
\hline$m$-Xylene & 0.08 & 0.10 & 0.08 & & 0.14 & \\
\hline tert-Butyl-m-xylene & 0.07 & 0.01 & 0.07 & & 0.01 & \\
\hline tert-Butylbenzene & 0.19 & 0.08 & 0.19 & & 0.11 & \\
\hline Benzene & 0.03 & 0.34 & 0.03 & & 0.22 & \\
\hline$p$-Xylene & 0.34 & 0.47 & 0.34 & & 0.5 & \\
\hline
\end{tabular}

matrix and stoichiometric matrix of the system are given by:

$$
\mathbf{A}=\left[\begin{array}{llllll}
1 & 0 & 0 & 1 & 1 & 0 \\
2 & 0 & 1 & 1 & 0 & 0 \\
0 & 1 & 1 & 0 & 0 & 0 \\
0 & 0 & 0 & 0 & 0 & 1
\end{array}\right] \quad \mathbf{N}=\left[\begin{array}{cccccc}
-1 & -1 & 1 & 0 & 0 \\
0 & -1 & 1 & -1 & 1 & 0
\end{array}\right]^{\mathrm{T}}
$$

Vapor and liquid phases are ideal. Chemical equilibrium constants and vapor pressure expressions were taken from Saito et al. (1971). The authors determined experimentally compositions at different plates in two distillation columns: lower pressure alkylation column of $m$-xylene and higher pressure recovery column of $m$-xylene and alkylating reagent. Bubble point calculations are performed for the 1st plate/condenser of the column and compared with the experimental compositions (Saito et al. 1971) in Tables 2 and 3 . At both temperatures, highest deviations are noted for benzene. In Figure 3 for the same feed compositions, we present the temperature range of the 2-phase system, as well as the mole fractions of each component. Most mole fractions curves exhibit monotonic behavior. Although xylene isomer compositions might have maxima in the two different pressures and phases, $p$-xylene shows the clearest maximum at $347.52 \mathrm{~K}$ and $44 \mathrm{mmHg}$ with a vapor phase composition of $y_{6}=0.557$. 
Table 3: Mole fractions in xylene separation at the bubble point of $86 \mathrm{mmHg}$.

\begin{tabular}{|c|c|c|c|c|c|c|}
\hline \multirow[t]{2}{*}{ Component } & \multirow[t]{2}{*}{ Feed } & \multicolumn{2}{|c|}{ Our work $-324.40 \mathrm{~K}$} & Saito et al. & $(1971)$ & $-323.15 \mathrm{~K}$ \\
\hline & & Vapor & Liquid & & Vapor & \\
\hline Di-tert-butylbenzene & 0.09 & 0.00 & 0.07 & & 0.00 & \\
\hline$m$-Xylene & 0.35 & 0.13 & 0.34 & & 0.29 & \\
\hline tert-Butyl-m-xylene & 0.04 & 0.00 & 0.05 & & 0.00 & \\
\hline tert-Butylbenzene & 0.21 & 0.03 & 0.24 & & 0.05 & \\
\hline Benzene & 0.25 & 0.82 & 0.24 & & 0.59 & \\
\hline$p$-Xylene & 0.06 & 0.02 & 0.06 & & 0.07 & \\
\hline
\end{tabular}

Ung and Doherty (1995e) studied the phase behavior of methyl-tert-butyl ether (MTBE) synthesis from isobutene and methanol in the presence of $n$ butane as an inert:

$$
\mathrm{C}_{4} \mathrm{H}_{8}+\mathrm{CH}_{4} \mathrm{O} \rightleftharpoons \mathrm{C}_{5} \mathrm{H}_{12} \mathrm{O}
$$

The number of elements is $N_{E}=N_{C}-N_{R}=4-1=3$. The formula matrix and stoichiometric matrix of the system are given by:

$$
\mathbf{A}=\left[\begin{array}{llll}
1 & 0 & 0 & 1 \\
0 & 1 & 0 & 1 \\
0 & 0 & 1 & 0
\end{array}\right] \quad \mathbf{N}=\left[\begin{array}{llll}
-1 & -1 & 0 & 1
\end{array}\right]^{\mathrm{T}}
$$

Vapor phase is considered ideal and liquid phase is described by the Wilson activity coefficient model (Wilson, 1964). The chemical equilibrium constant, vapor pressure expressions and parameters for the Wilson model were taken from Ung and Doherty (1995e). At a reactive azeotrope, Ung and Doherty 295 (1995b) proved that mole fractions in the two phases are not necessarily equal. Instead, they introduce a set of transformed composition variables, denoted by capital letters, which simplifies the analysis. According to their new notation, at a reactive azeotrope $X=Y$ for all reference components. For this system, 


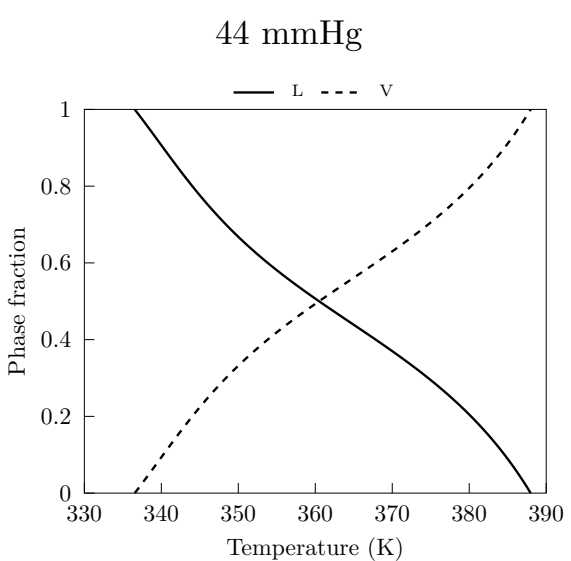

(a)

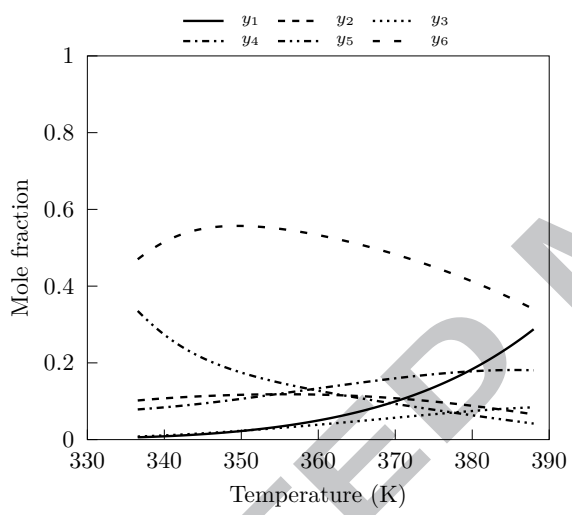

(c)

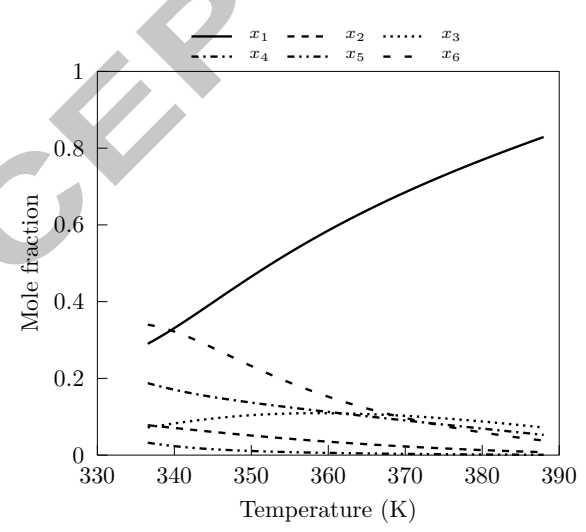

(e)

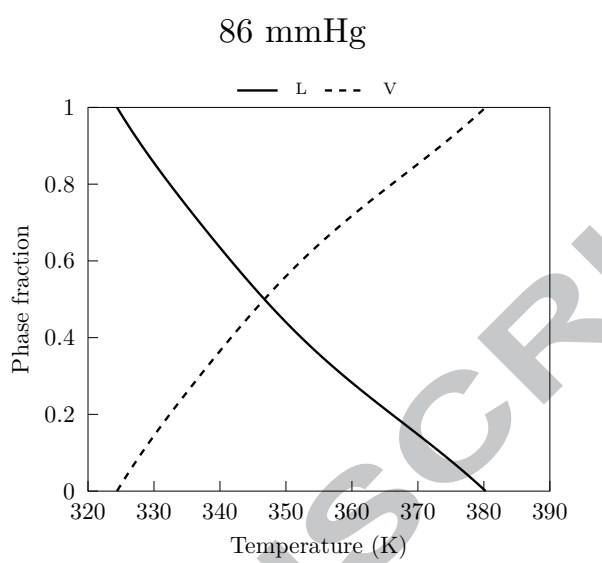

(b)

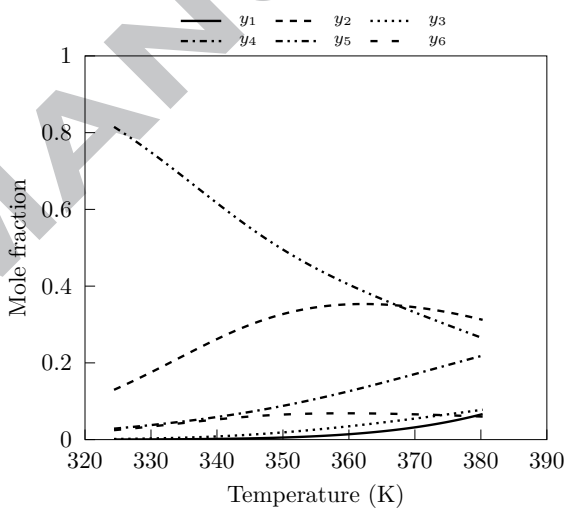

(d)

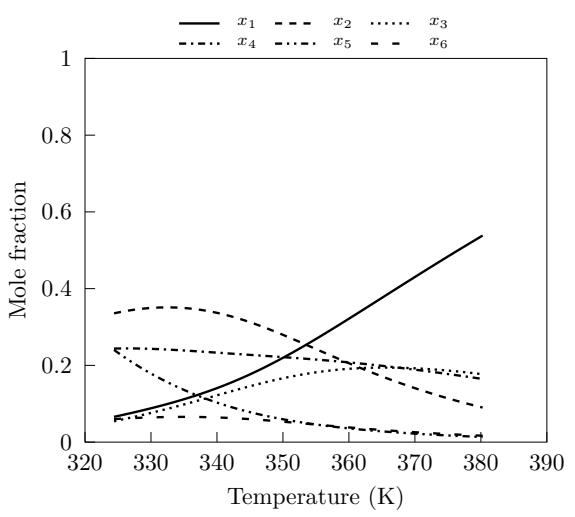

(f)

Figure 3: Phase fractions (a, b) and mole fractions (c, d, e, f) in xylene separation for the feeds reported in Tables 2 and 3 
transformed compositions are found by:

$$
X_{1}=\frac{x_{1}+x_{4}}{1+x_{4}} \quad X_{2}=\frac{x_{2}+x_{4}}{1+x_{4}} \quad X_{3}=\frac{x_{3}}{1+x_{4}}
$$

In the two-phase region, the phase compositions of MTBE and $n$-butane (Figures $5 \mathrm{~d}$ and 5 ) change only slightly. However, the overall mole fraction of MTBE (the total moles of MTBE divided by the total moles of the components in the system) decreases continuously as a result of the dilution by the inert 325 component. referred to Ung and Doherty (1995b d). The equilibrium diagrams at 1 atm are presented in Figures 4 and $4 \mathrm{~b}$ using transformed compositions. The inert was not considered in these calculations. An "intermediate-boiling inflection azeotrope" is identified, or according to Ung and Doherty (1995e), a "pseudoreactive azeotrope", for being fairly close to the diagonal (Figure 4b). We observed this point at $320.92 \mathrm{~K}$. In Figure 4 , we find that the maximum MTBE concentrations are $y_{4}=0.70$ in the vapor phase at $320.56 \mathrm{~K}$ and $x_{4}=0.93$ in the liquid phase at $317.70 \mathrm{~K}$. The absence of the inert allows us to depict all the equilibrium curves in two-dimensional diagrams.

We also examined the inert effect in the following conditions: $300 \mathrm{~K}$ and 1 atm with an equimolar feed of reactants (isobutene and methanol, 1 mol each). Different values of mole numbers for the inert were included in this feed and the effects on the overall equilibrium are presented in Figure 5. Phase fractions and mole fractions of all the components are shown, as the inert concentration increases in the feed. The vapor pressure expression constants for $n$-butane were taken from NIST Chemistry WebBook (Accessed: 19.02.2016). Since the inert is volatile, a vapor phase appears with the addition of approximately 0.36 mol of $n$-butane, after which the vapor phase fraction increases with $n$-butane concentration until we obtain $100 \%$ vapor. The mole fraction of MTBE (Figure 5 ) for a single phase decreases as the moles of the inert in the feed increase. 


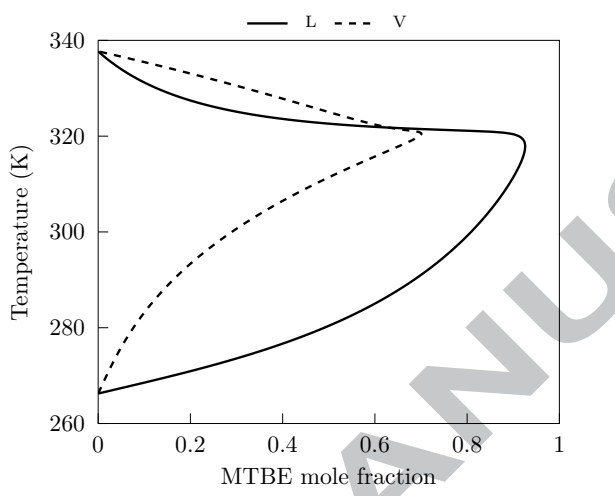

(a)

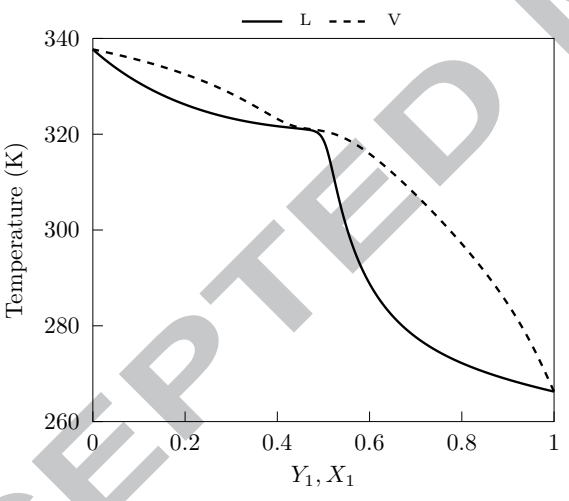

(b)

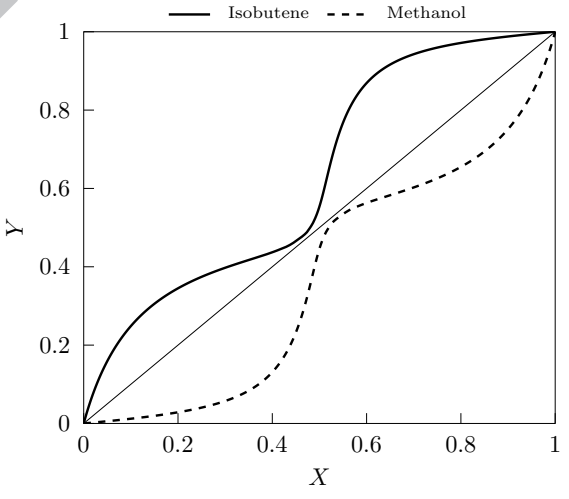

(c)

Figure 4: Equilibrium $T-y$ - $x$ diagram for $\operatorname{MTBE}(\mathrm{a}), T-Y-X$ diagram for isobutene (b) and $Y-X$ diagram for isobutene and methanol (c) in MTBE synthesis at $1 \mathrm{~atm}$. 


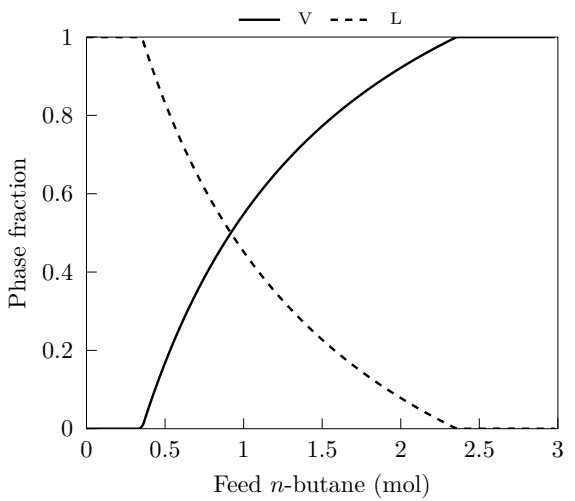

(a)

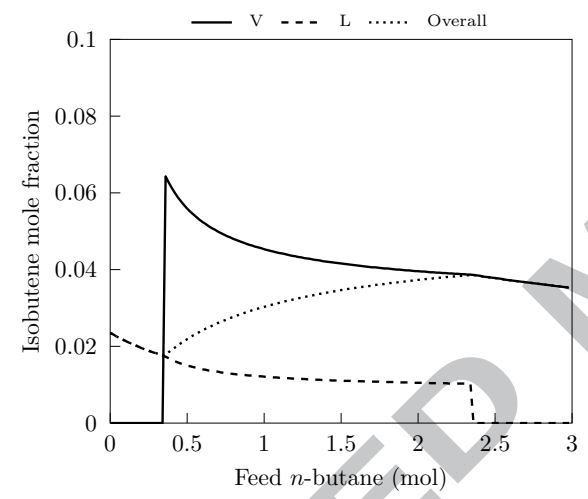

(b)

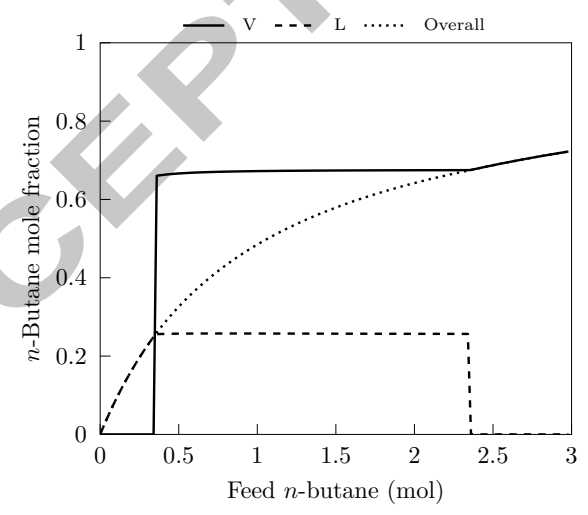

(d)

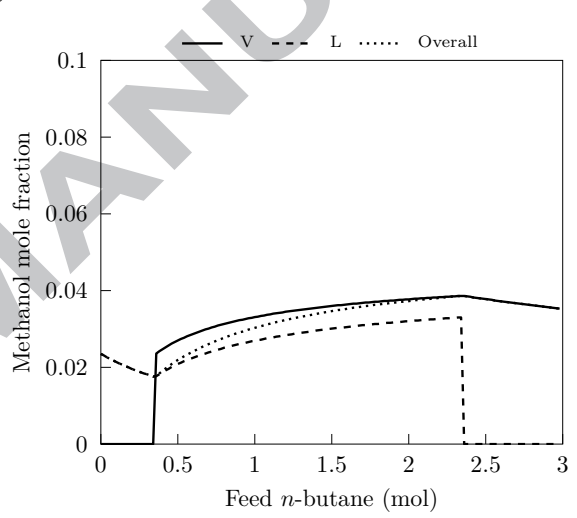

(c)

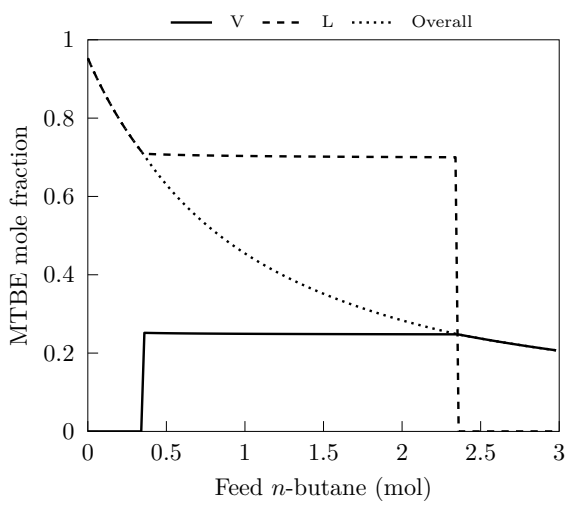

(e)

Figure 5: Phase fractions (a), mole fractions of isobutene (b), methanol (c), $n$-butane (d) and MTBE (e) as a function of $n$-butane moles in the feed for the MTBE synthesis at $300 \mathrm{~K}$ and $1 \mathrm{~atm}$. 


\subsection{Esterification of acetic acid and ethanol}

One of the most studied esterification reactions is between acetic acid and ethanol producing ethyl acetate and water:

$$
\mathrm{C}_{2} \mathrm{H}_{4} \mathrm{O}_{2}+\mathrm{C}_{2} \mathrm{H}_{6} \mathrm{O} \rightleftharpoons \mathrm{C}_{4} \mathrm{H}_{8} \mathrm{O}_{2}+\mathrm{H}_{2} \mathrm{O}
$$

The number of elements is $N_{E}=N_{C}-N_{R}=4-1=3$. The formula matrix and stoichiometric matrix of the system are given by:

$$
\mathbf{A}=\left[\begin{array}{llll}
1 & 0 & 0 & 1 \\
0 & 1 & 0 & 1 \\
1 & 0 & 1 & 0
\end{array}\right] \quad \mathbf{N}=\left[\begin{array}{llll}
-1 & -1 & 1 & 1
\end{array}\right]^{\mathrm{T}}
$$

Vapor phase is considered ideal and liquid phase is described by the UNIQUAC activity coefficient model (Abrams and Prausnitz, 1975). The chemical equilibrium constant, vapor pressure expressions and parameters for the UNIQUAC model were taken from Xiao et al. (1989). Castier et al. (1989) studied this system including the competing etherification reaction of ethanol to diethylether as well as the dimerization of acetic acid in the vapor phase. Comparisons are made with the results of Xiao et al. (1989), and Stateva and Wakeham (1997) in Table 4 . Larger deviations with Stateva and Wakeham (1997) could be attributed to selecting a different source for the chemical equilibrium constant. In Figure 6 phase boundaries and mole fractions are presented for an equimolar feed of the reactants.

\subsection{Cyclohexane synthesis}

George et al. (1976) examined the hydrogenation of benzene at high temperature for cyclohexane synthesis:

$$
\mathrm{C}_{6} \mathrm{H}_{6}+3 \mathrm{H}_{2} \rightleftharpoons \mathrm{C}_{6} \mathrm{H}_{12}
$$




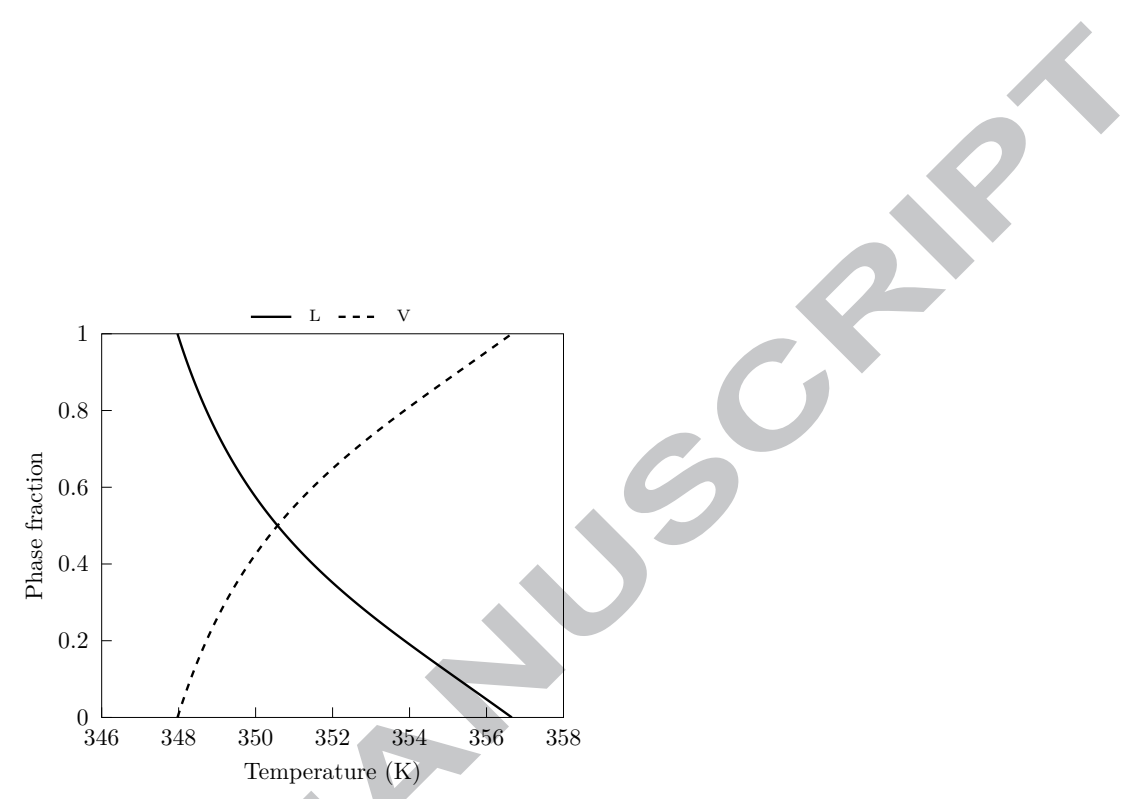

(a)

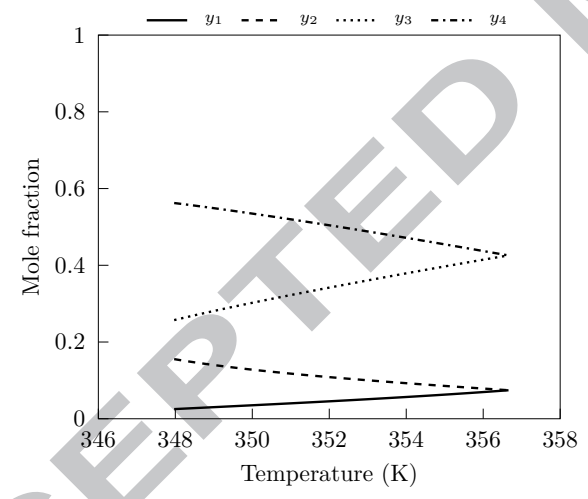

(b)

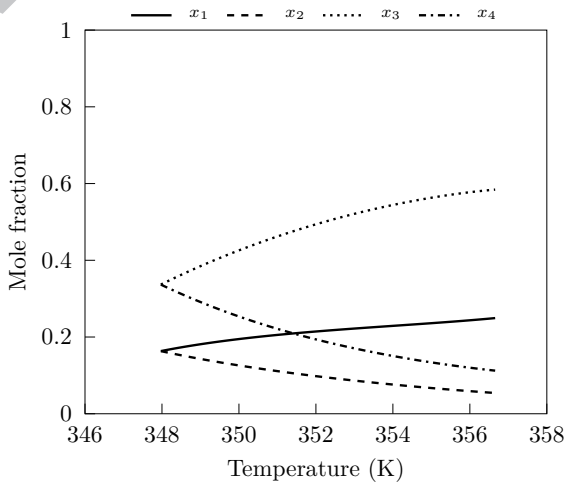

(c)

Figure 6: Phase fractions (a) and mole fractions (b, c) in acetic acid/ethanol esterification for an equimolar feed of reactants at $1 \mathrm{~atm}$. 
Table 4: Mole fractions, phase amounts and phase fractions in acetic acid/ethanol esterification at $355 \mathrm{~K}$ and $1 \mathrm{~atm}$.

\begin{tabular}{|c|c|c|c|c|c|c|c|}
\hline \multirow[t]{2}{*}{ Component } & \multirow[t]{2}{*}{ Feed } & \multicolumn{2}{|c|}{ Our work } & \multicolumn{2}{|c|}{ Stateva and Wakeham } & \multirow[t]{2}{*}{1997} & Xiao et al. 1989 \\
\hline & & Vapor & Liquid & Vapor & Liquid & & Vapor \\
\hline Acetic acid & 0.5 & 0.0629 & 0.2360 & 0.0554 & 0.2243 & & $0.0624 \quad 0.2376$ \\
\hline Ethanol & 0.5 & 0.0855 & 0.0670 & 0.1029 & 0.0675 & & $0.0862 \quad 0.0686$ \\
\hline Water & 0 & 0.3970 & 0.5630 & 0.3604 & 0.5537 & & 0.3963 \\
\hline Ethyl acetate & 0 & 0.4545 & 0.1339 & 0.4813 & 0.1545 & & $0.4551 \quad 0.1373$ \\
\hline$n_{t}(\mathrm{~mol})$ & 20 & 17.636 & 2.364 & & & & \\
\hline$\beta$ & & 0.882 & 0.118 & 0.767 & 0.233 & & 0.123 \\
\hline
\end{tabular}

345 The number of elements is $N_{E}=N_{C}-N_{R}=3-1=2$. The formula matrix and stoichiometric matrix of the system are given by:

$$
\mathbf{A}=\left[\begin{array}{lll}
1 & 0 & 1 \\
0 & 1 & 3
\end{array}\right] \quad \mathbf{N}=\left[\begin{array}{lll}
-1 & -3 & 1
\end{array}\right]^{\mathrm{T}}
$$

a Phase behavior is described by the Peng-Robinson equation of state (Peng and Robinson, 1976) without binary interaction parameters $\left(k_{i j}=0\right)$, similar to Burgos-Solórzano et al. (2004). Gibbs energy of formation was taken from

350 George et al. (1976). Calculations are shown in Table 5. Small differences with Burgos-Solórzano et al. (2004) are attributed to selecting a different source for the chemical equilibrium constant. George et al. (1976) assumed that the system obeys the Lewis fugacity rule, underestimating the influence of intermolecular forces, hence predicting larger vapor phase amount.

\subsection{Methanol synthesis}

Methanol can be synthesized from a mixture containing carbon monoxide, carbon dioxide, hydrogen and water, according to the reactions: 
Table 5: Mole fractions, phase amounts and phase fractions in cyclohexane synthesis at 500 $\underline{\mathrm{K}}$ and $30 \mathrm{~atm}$.

\begin{tabular}{|c|c|c|c|c|c|c|c|}
\hline \multirow[t]{2}{*}{ Component } & \multirow[t]{2}{*}{ Feed } & \multicolumn{2}{|c|}{ Our work } & \multicolumn{2}{|c|}{ Burgos-Solórzano et al. (2004) } & \multicolumn{2}{|c|}{ George et al. (1976) } \\
\hline & & Vapor & Liquid & Vapor & Liquid & Vapor & Liquid \\
\hline Benzene & 0.247 & $4.45 \times 10^{-6}$ & $5.43 \times 10^{-6}$ & $4.00 \times 10^{-6}$ & $4.92 \times 10^{-6}$ & $3.64 \times 10^{-4}$ & $3.87 \times$ \\
\hline Hydrogen & 0.753 & 0.238 & 0.0204 & 0.249 & 0.0147 & 0.076 & 0.00 \\
\hline Cyclohexane & 0 & 0.762 & 0.980 & 0.751 & 0.985 & 0.923 & \\
\hline$n_{t}(\mathrm{~mol})$ & 4.05 & 0.132 & 0.918 & 0.148 & 0.902 & 0.660 & 0.391 \\
\hline$\beta$ & & 0.125 & 0.875 & 0.141 & 0.859 & 0.628 & 0.372 \\
\hline
\end{tabular}

$$
\begin{gathered}
\mathrm{CO}+2 \mathrm{H}_{2} \rightleftharpoons \mathrm{CH}_{4} \mathrm{O} \\
\mathrm{CO}_{2}+\mathrm{H}_{2} \rightleftharpoons \mathrm{CO}+\mathrm{H}_{2} \mathrm{O}
\end{gathered}
$$

Methane and octadecane are included as inerts. The number of elements is $N_{E}=N_{C}-N_{R}=7-2=5$. The formula matrix and stoichiometric matrix of the system are given by:

$$
\mathbf{A}=\left[\begin{array}{lllllll}
1 & 1 & 0 & 0 & 1 & 0 & 0 \\
0 & 1 & 0 & 1 & 0 & 0 & 0 \\
0 & 0 & 1 & 1 & 2 & 0 & 0 \\
0 & 0 & 0 & 0 & 0 & 1 & 0 \\
0 & 0 & 0 & 0 & 0 & 0 & 1
\end{array}\right] \quad \mathbf{N}=\left[\begin{array}{ccccccc}
-1 & 0 & -2 & 0 & 1 & 0 & 0 \\
1 & -1 & -1 & 1 & 0 & 0 & 0
\end{array}\right]^{\mathrm{T}}
$$

Phase behavior is described by the Soave-Redlich-Kwong equation of state (Soave, 1972) with binary interaction parameters $k_{i j}$ from Castier et al. (1989). Ideal gas chemical potentials at 1 bar (reference state) were taken from Phoenix and Heidemann (1998). In Tables 6 and 7, two different feeds are used to 365 produce methanol, resulting in a 2- and 3-phase system respectively. Results from Stateva and Wakeham (1997), and Castier et al. (1989) are also included for comparison. Introduction of the heavy hydrocarbon results in two immiscible liquid phases along with the vapor phase. For identification purposes, we named 
Table 6: Mole fractions, phase amounts and phase fractions in methanol synthesis at 473.15 $\mathrm{K}$ and $300 \mathrm{bar}$

\begin{tabular}{|c|c|c|c|c|c|c|c|}
\hline \multirow[t]{2}{*}{ Component } & \multirow[t]{2}{*}{ Feed } & \multicolumn{2}{|c|}{ Our work } & \multicolumn{2}{|c|}{ Stateva and Wakeham (1997) } & \multicolumn{2}{|c|}{ Castier et al. (1989) } \\
\hline & & Vapor & Liquid & Vapor & Liquid & Vapor & Liquid \\
\hline Carbon monoxide & 0.15 & $6.27 \times 10^{-5}$ & $1.09 \times 10^{-5}$ & $1.33 \times 10^{-5}$ & traces & $6.51 \times 10^{-5}$ & $1.08 \times 10$ \\
\hline Carbon dioxide & 0.08 & 0.0006 & 0.0003 & traces & traces & 0.0005 & 0.0002 \\
\hline Hydrogen & 0.74 & 0.6597 & 0.0970 & 0.6493 & 0.0948 & 0.6589 & 0.0962 \\
\hline Water & 0 & 0.0471 & 0.2432 & 0.0464 & 0.2488 & 0.0473 & 0.24 \\
\hline Methanol & 0 & 0.2045 & 0.6349 & 0.2120 & 0.6371 & 0.2053 & 0.6354 \\
\hline Methane & 0.3 & 0.0880 & 0.0246 & 0.0923 & 0.0193 & 0.0878 & 0.0246 \\
\hline Octadecane & 0 & 0 & 0 & 0 & 0 & & 0 \\
\hline$n_{t}(\mathrm{~mol})$ & 100 & 26.346 & 27.702 & & & 26.421 & 27.622 \\
\hline$\beta$ & & 0.4875 & 0.5125 & 0.4968 & 0.5032 & 0.4889 & 0.5111 \\
\hline
\end{tabular}

Table 7: Mole fractions, phase amounts and phase fractions in methanol synthesis at 473.15 $\underline{\mathrm{K}}$ and $101.3 \mathrm{bar}$.

\begin{tabular}{|c|c|c|c|c|c|c|c|c|c|c|}
\hline \multirow[t]{2}{*}{ Component } & \multirow[t]{2}{*}{ Feed } & \multicolumn{3}{|c|}{ Our work } & \multicolumn{2}{|c|}{ Stateva and Wakeham } & \multicolumn{2}{|l|}{ 1997) } & \multicolumn{2}{|c|}{ Castier et al. 1989, } \\
\hline & & Vapor & Liquid (aq) & Liquid (org) & Vapor & Liquid (aq) & Liquid (org) & Vapor & Liquid (aq) & Liquid (org) \\
\hline Carbon monoxide & 0.1071 & 0.0010 & $7.00 \times 10^{-6}$ & 0.0002 & $5.63 \times 10^{-8}$ & $1.27 \times 10^{-10}$ & $4.80 \times 10^{-9}$ & 0.0011 & $6.82 \times 10^{-6}$ & 0.0002 \\
\hline Carbon dioxide & 0.0571 & 0.0548 & 0.0025 & 0.0271 & $7.27 \times 10^{-12}$ & $2.96 \times 10^{-6}$ & $3.18 \times 10^{-12}$ & 0.0534 & 0.0024 & 0.0270 \\
\hline Hydrogen & 0.5286 & 0.5741 & 0.0059 & 0.1091 & 0.5328 & 0.0071 & 0.0600 & 0.5731 & 0.0058 & 0.1159 \\
\hline Water & 0.2143 & 0.1718 & 0.7715 & 0.1104 & 0.1635 & 0.7047 & 0.0070 & 0.1722 & 0.7709 & 0.1116 \\
\hline Methanol & 0 & 0.1426 & 0.2197 & 0.2767 & 0.2274 & 0.2870 & 0.1418 & 0.1441 & 0.2205 & 0.2753 \\
\hline Methane & 0.0214 & 0.0544 & 0.0004 & 0.0182 & 0.0752 & 0.0011 & 0.0210 & 0.0546 & 0.0004 & 0.0192 \\
\hline Octadecane & 0.0715 & 0.0014 & & 0.4582 & 0.0010 & $2.70 \times 10^{-6}$ & 0.7702 & 0.0015 & $1.31 \times 10^{-15}$ & 0.4507 \\
\hline$n_{t}(\mathrm{~mol})$ & 140 & 47.702 & 31.285 & 21.673 & & & & 46.917 & 31.508 & 22.030 \\
\hline$\beta$ & & 0.4739 & 0.3108 & 0.2153 & 0.4843 & 0.3780 & 0.1377 & 0.4670 & 0.3136 & 0.2193 \\
\hline
\end{tabular}

the water-rich phase "aqueous" and the hydrocarbon-rich phase "organic". Both 370 Stateva and Wakeham (1997), and Castier et al. (1989) use chemical equilibrium constants from different sources. Results, especially compositions, are closer to those reported by Castier et al. (1989) for the 2-phase as well as the 3-phase mixture.

\subsection{Convergence and speed}

Convergence rate was examined for the initialization procedure as well as the main algorithm. In Figures $7 \mathrm{a}, 7 \mathrm{~b}$ and $7 \mathrm{k}$, convergence at the pseudoreactive azeotrope of MTBE synthesis is tested. Initializing the calculations 
follows a quadratic convergence rate (minimization of $Q$ function, Eq. 31). The single-phase reaction requires a small number of iterations. Stability identifies to result in slower calculations compared with a cubic EoS, as PR or SRK. The fastest calculations are for ideal systems, where the outer loop (non-ideality update) is not needed.

For the chemical and phase equilibrium calculation algorithms in the litera405 ture, their computational efficiencies are often reported in terms of CPU times and/or iteration numbers. However, it is not always straightforward to compare various algorithms based on these performance indices, because they can be influenced by many factors: The CPU times depend on the hardware, the 


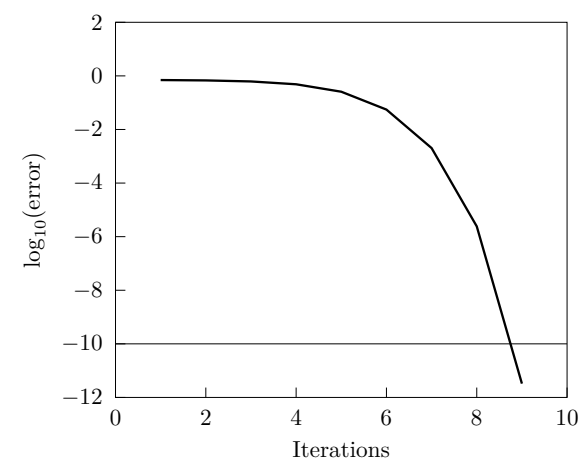

(a)

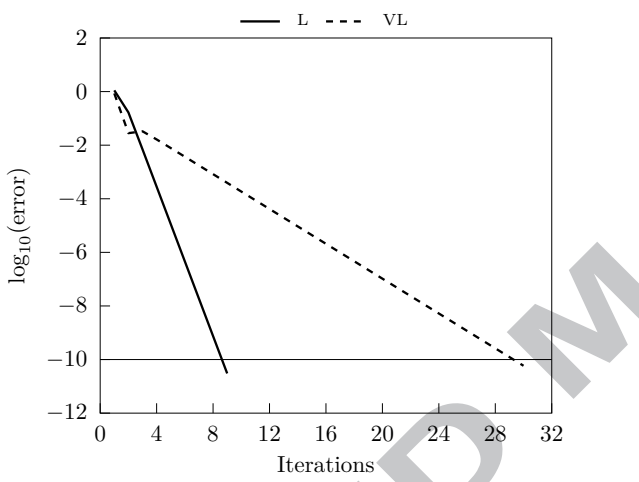

(b)

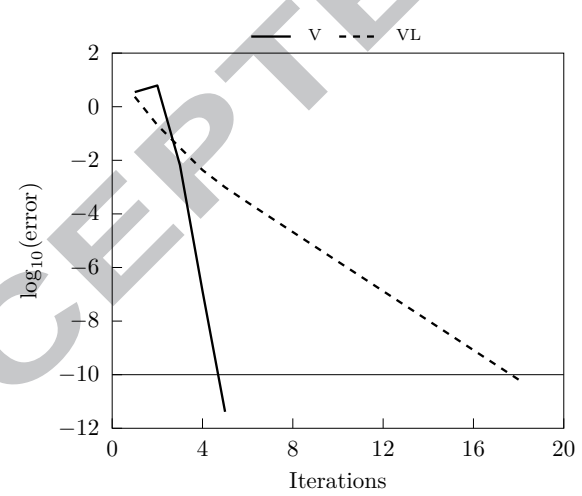

(d)

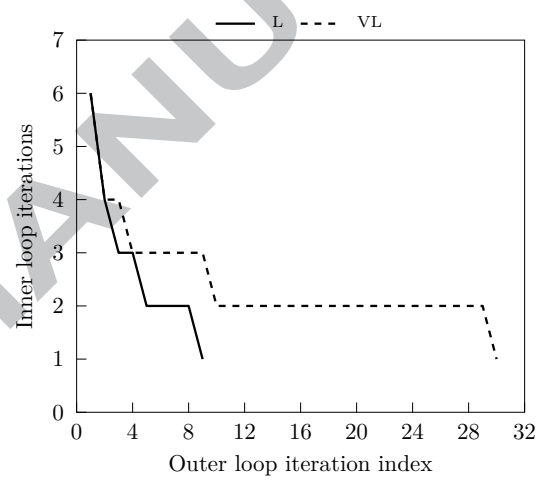

(c)

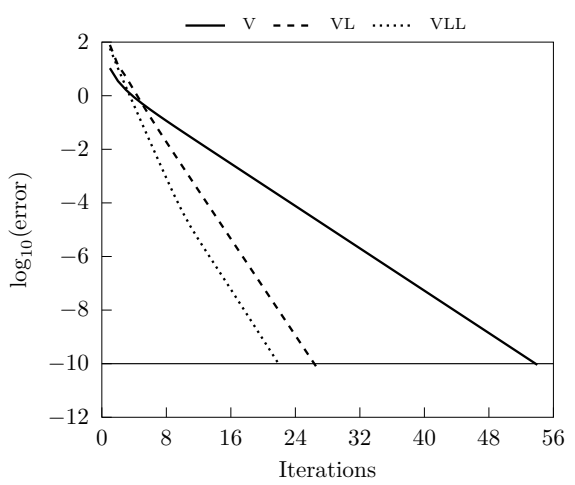

(e)

Figure 7: Convergence behavior of MTBE synthesis at $320.92 \mathrm{~K}$ and 1 atm (isobutene/methanol 1:1.1) for $Q$ function minimization (a) overall CPE (b), and inner loop (Newton) iterations per outer loop non-ideality updates (c), cyclohexane synthesis at $500 \mathrm{~K}$ and $30 \mathrm{~atm}(\mathrm{~d})$, and 3-phase methanol synthesis at $473.15 \mathrm{~K}$ and $101.3 \mathrm{bar}(\mathrm{e})$. 
Table 8: CPU time for determining the equilibrium solution of the systems examined (Intel@) Core $^{\mathrm{TM}}$ i7-5500U CPU@ $\left.2.40 \mathrm{GHz}\right)$.

\begin{tabular}{|c|c|c|c|c|c|}
\hline System & $T(\mathrm{~K})$ & $p$ & $\mathbf{n}_{F}(\mathrm{~mol})$ & CPU time (ms) & Notes \\
\hline Formaldehyde/water & 310 & $1 \mathrm{~atm}$ & {$\left[\begin{array}{llll}1 & 1 & 0 & 0\end{array}\right]^{\mathrm{T}}$} & 1.28 & Ideal V \& L \\
\hline Xylene separation & 350 & $0.05 \mathrm{~atm}$ & {$\left[\begin{array}{llllll}1 & 1 & 0 & 0 & 0 & 1\end{array}\right]^{\mathrm{T}}$} & 1.31 & Ideal V \& L \\
\hline MTBE synthesis & 320.92 & $1 \mathrm{~atm}$ & {$\left[\begin{array}{llll}1 & 1.1 & 0 & 0\end{array}\right]^{\mathrm{T}}$} & 1.87 & Ideal V, Wilson for $\mathrm{L}$ \\
\hline Acetic acid/ethanol esterification & 355 & $1 \mathrm{~atm}$ & {$\left[\begin{array}{llll}1 & 1 & 0 & 0\end{array}\right]^{\mathrm{T}}$} & 1.72 & Ideal $\mathrm{V}$, UNIQUAC for $\mathrm{L}$ \\
\hline Cyclohexane synthesis & 500 & $30 \mathrm{~atm}$ & {$\left[\begin{array}{lll}1 & 3.05 & 0\end{array}\right]^{\mathrm{T}}$} & 1.48 & $\mathrm{PR}$ \\
\hline Methanol synthesis & 473.15 & $101.3 \mathrm{bar}$ & {$\left[\begin{array}{lllllll}15 & 8 & 74 & 30 & 3 & 0 & 10\end{array}\right]^{\mathrm{T}}$} & 3.08 & SRK \\
\hline
\end{tabular}

computer language used, and the compiler; the iteration numbers depend on the

initial estimates and the tolerances for the convergence criteria. Furthermore, the cost for single iteration can be very different for different algorithms. Nevertheless, we provide below a comparison of CPU times or iteration numbers with some reported values in the literature. The readers should consider the differences in the factors that may influence the CPU times or iteration numbers in the following comparison:

- MTBE synthesis (Castier et al. 1989)

The authors use a method consisting of initialization steps with direct substitution accelerated by the General Dominant Eigenvalue Method (GDEM) Crowe and Nishio 1975 and Murray's minimization for final convergence. They suggested 5 direct substitution iterations followed by 1 GDEM step for the single-phase chemical equilibrium, 2 GDEM steps for two-phase systems and 3 GDEM steps for three-phase systems (unless certain criteria are met to enter Murray's minimization). The Murray steps are used only for the final convergence, thus are very efficient.

Their calculations for this system are at different conditions from this work: temperatures corresponding to the two-phase region at 5.07 bar with 1-butene as inert, instead of $n$-butane. They reported 2 Murray iterations for the single-phase convergence and 1 Murray iteration for the two-phase system. No further information was given for the initialization iterations. Our calculations required 9 outer loop iterations (with a total of 25 Newton 
iterations) to converge the liquid phase and 30 outer loop iterations (with a total of 73 Newton iterations) to converge the vapor-liquid system. The authors can reach quadratic convergence rates, and therefore their method is expected to be faster than the algorithm presented here.

- Cyclohexane synthesis (Burgos-Solórzano et al. 2004)

The authors use a validation tool, a deterministic mathematical method that guarantees finding the global minimum of the Gibbs energy. They reported $120 \mathrm{~ms}$ required for the validation tool calculations [Sun Blade 1000 Model 1600 (600 MHz) workstation], whereas we spent $1.5 \mathrm{~ms}$ for the complete calculations (initialization, convergence of single phase, stability analysis, convergence of two-phase system and final stability analysis).

- Acetic acid/ethanol esterification (Xiao et al, 1989, Castier et al., 1989) Xiao et al. (1989) compared two stoichiometric methods, the S-C and the $\mathrm{KZ}$ algorithm. The S-C algorithm is the classical stoichiometric approach using nested loops. Its inner loop solves the phase equilibrium problem (flash) using a successive substitution approach based on the RachfordRice equation, while its outer loop updates the extents of reaction. The $\mathrm{KZ}$ algorithm, proposed as an improvement of the S-C algorithm, switches the outer and inner loops in the S-C algorithm. They reported 10 outer loop iterations (with a total of 42 Newton iterations) for the S-C algorithm and 9 outer loop iterations (with a total of 23 Newton iterations) for the KZ algorithm. In our work, after 8 Newton iterations of the initialization procedure, the solution obtained coincides with the single vapor phase solution and the main solver was not needed. For the VLE of this reaction system we needed 44 outer loop iterations (with a total of 106 Newton iterations). In Xiao et al. (1989), the initial assumption is a two-phase system. Since all the three algorithms (S-C, KZ and ours) are supposed to show an overall linear convergence, their iteration numbers should in principle be comparable. We note that in Xiao et al. (1989) a very loose tolerance is used for the convergence, $\sum_{i=1}^{N_{C}}\left(k_{i}^{\text {new }} / k_{i}-1\right)^{2}<10^{-6}$, where 
$k_{i}=y_{i} / x_{i}$. In our solution, a much tighter convergence criterion is used (Eq. 39.).

Castier et al. (1989) used a slightly higher temperature than the one presented in this work: $358.15 \mathrm{~K}$. The ideal gas assumption for the vapor phase resulted in a single vapor phase at equilibrium that required 3 Murray iterations. On the other hand, using an EoS that accounts for the acid dimerization in the vapor phase, convergence required 3 Murray iterations for the initially assumed single vapor phase and 2 Murray iterations for the final vapor-liquid system.

- Methanol synthesis (Castier et al., 1989)

For the three-phase synthesis, all phase sets are initialized in Castier et al. (1989): L, VL and VLL required 5 iterations with 1 GDEM step, 10 iterations with 2 GDEM steps, and 12 iterations with 2 GDEM steps respectively (the third GDEM step was not needed for the three-phase convergence). The Murray iterations to converge L, VL and VLL systems were 3,4 and 1 respectively. We needed 10 Newton iterations for the initialization of the single-phase system, and after stability introduced additional phases, we did not initialize again. For our CPE calculations, we needed 54 outer loop iterations (with a total of 149 Newton iterations) for $\mathrm{V}, 27$ outer loop iterations (with a total of 78 Newton iterations) for VL and 22 outer loop iterations (with a total of 60 Newton iterations) for VLL. In our algorithm, no acceleration was implemented.

\subsection{Alternative treatment}

We have minimized $Q$ function (Eq. 31) for a single ideal phase to initialize $\boldsymbol{\lambda}$ for the nested-loop calculations, by keeping the phase amount at a fixed value. Alternatively, this minimization could be attempted considering a set of non-ideal phases $\left(N_{P}>1\right)$, where the fugacity/activity coefficients are assumed composition independent. Every time a new phase is introduced, fugacity/activity coefficients are calculated for the current composition estimate 
where straint:

and kept constant during the minimization. Because $\nabla^{2} Q$ is still positive definite, finding the unique minimizer is a safe procedure that requires a finite number of iterations.

To reduce the number of iterations, an accelerated successive substitution method could be utilized. The General Dominant Eigenvalue Method (GDEM)

(Crowe and Nishio, 1975) is a possible candidate. Although acceleration is needed to enhance the efficiency of calculations, the material balance is one of the working equations, meaning that the independent variables do not obey it at every iteration. As a result, the values of $G=f\left(\boldsymbol{\lambda}, \mathbf{n}_{t}\right)$ cannot be used to validate, if the acceleration actually leads to a decrease in the Gibbs energy.

a The RAND approach (White et al., 1958, Greiner, 1991, Michelsen and Mollerup, 2007) can also be used to increase the convergence rate. The method of Lagrange multipliers discussed in this work can be employed as initial converging steps, before switching to the quadratically convergent RAND algorithm. We will discuss how to apply the RAND approach to non-ideal multiphase and multiple reaction systems in a separate paper.

In a completely different formulation of the problem, the Gibbs energy is minimized with respect to extents of reactions $\xi_{r}$ under the non-negativity con-

$$
\begin{array}{ll} 
& \min _{\boldsymbol{\xi}} G(T, p, \boldsymbol{\xi}) \\
\text { s.t. } & n_{i k} \geq 0, \quad i=1, \ldots, N_{C} \quad k=1, \ldots, N_{P}
\end{array}
$$

$$
\sum_{k=1}^{N_{P}} n_{i k}=n_{F, i}+\sum_{r=1}^{N_{R}} \nu_{i r} \xi_{r}
$$

510 If we do not account directly for the non-negativity constraints, this formulation is essentially an unconstrained minimization problem and can be advantageous for a small number of reactions. However, there are initialization problems and the method is prone to round-off errors. To overcome this obstacle, we can select $N_{E}$ components as the "optimum" basis, the primary components, which are 

of systems described by different thermodynamic models. The convergence rate is linear, due to the successive substitution in the outer loop. Nevertheless, the method appears to be robust, without failing solving CPE for all the systems examined.

\section{Acknowledgments}

We would like to acknowledge the help of Prof. Michael L. Michelsen for his insightful comments and suggestions.

\section{References}

Abrams, D.S., Prausnitz, J.M., 1975. Statistical thermodynamics of liquid mix540 tures: A new expression for the excess gibbs energy of partly or completely miscible systems. AIChE Journal 21, 116-128. 
Barbosa, D., Doherty, M.F., 1988. The influence of equilibrium chemical reactions on vapor-liquid phase diagrams. Chemical Engineering Science 43, $529-540$.

Bonilla-Petriciolet, A., Rangaiah, G.P., Segovia-Hernández, J.G., 2011. Constrained and unconstrained Gibbs free energy minimization in reactive systems using genetic algorithm and differential evolution with tabu list. Fluid Phase Equilibria 300, 120-134.

Bonilla-Petriciolet, A., Segovia-Hernández, J.G., 2010. A comparative study of particle swarm optimization and its variants for phase stability and equilibrium calculations in multicomponent reactive and non-reactive systems. Fluid Phase Equilibria 289, 110-121.

Bonilla-Petriciolet, A., Vázquez-Román, R., Iglesias-Silva, G.A., Hall, K.R., 2006. Performance of stochastic global optimization methods in the calculation of phase stability analyses for nonreactive and reactive mixtures. Industrial \& Egineering Chemistry Research 45, 4764-4772.

Brinkley, Jr, S.R., 1946. Note on the conditions of equilibrium for systems of many constituents. The Journal of Chemical Physics 14, 563-564.

Brinkley, Jr, S.R., 1947. Calculation of the equilibrium composition of systems of many constituents. The Journal of Chemical Physics 15, 107-110.

Burgos-Solórzano, G.I., Brennecke, J.F., Stadtherr, M.A., 2004. Validated computing approach for high-pressure chemical and multiphase equilibrium. Fluid Phase Equilibria 219, 245-255.

Castier, M., Rasmussen, P., Fredenslund, A., 1989. Calculation of simultaneous chemical and phase equilibria in nonideal systems. Chemical Engineering Science 44, 237-248.

Crowe, C.M., Nishio, M., 1975. Convergence promotion in the simulation of chemical processes - the general dominant eigenvalue method. AIChE Journal $21,528-533$. 
Floudas, C.A., Visweswaran, V., 1990. A global optimization algorithm (GOP) for certain classes of nonconvex NLPs-I. Theory. Computers \& Chemical Engineering 14, 1397-1417.

Fredenslund, A., Jones, R.L., Prausnitz, J.M., 1975. Group-contribution estimation of activity coefficients in nonideal liquid mixtures. AIChE Journal 21, 1086-1099.

Gautam, R., Seider, W.D., 1979a. Computation of phase and chemical equilibrium: Part I. Local and constrained minima in Gibbs free energy. AIChE Journal 25, 991-999.

Gautam, R., Seider, W.D., 1979b. Computation of phase and chemical equilibrium: Part II. Phase-splitting. AIChE Journal 25, 999-1006.

Gautam, R., Seider, W.D., 1979c. Computation of phase and chemical equilibrium: Part III. Electrolytic solutions. AIChE Journal 25, 1006-1015.

Gautam, R., Wareck, J.S., 1986 . Computation of physical and chemical equilibria-alternate specifications. Computers \& Chemical Engineering 10, $143-151$.

George, B., Brown, L.P., Farmer, C.H., Buthod, P., Manning, F.S., 1976. Computation of multicomponent, multiphase equilibrium. Industrial \& Engineering Chemistry Process Design and Development 15, 372-377.

Greiner, H., 1991. An efficient implementation of Newton's method for complex nonideal chemical equilibria. Computers \& Chemical Engineering 15, 115123.

Jalali, F., Seader, J.D., Khaleghi, S., 2008. Global solution approaches in equilibrium and stability analysis using homotopy continuation in the complex domain. Computers \& Chemical Engineering 32, 2333-2345.

595

Jalali-Farahani, F., Seader, J.D., 2000. Use of homotopy-continuation method in stability analysis of multiphase, reacting systems. Computers \& Chemical Engineering 24, 1997-2008. 
Maurer, G., 1986. Vapor-liquid equilibrium of formaldehyde-and watercontaining multicomponent mixtures. AIChE Journal 32, 932-948.

McDonald, C.M., Floudas, C.A., 1995. Global optimization for the phase and chemical equilibrium problem: Application to the NRTL equation. Computers \& Chemical Engineering 19, 1111-1139.

McDonald, C.M., Floudas, C.A., 1997. GLOPEQ: A new computational tool for the phase and chemical equilibrium problem. Computers \& Chemical Engineering 121, 1-23.

Michelsen, M.L., 1982. The isothermal flash problem. Part I. Stability. Fluid Phase Equilibria 9, 1-19.

Michelsen, M.L., 1989. Calculation of multiphase ideal solution chemical equilibrium. Fluid Phase Equilibria 53, 73-80.

Michelsen, M.L., Mollerup, J.M., 2007. Thermodynamic Models: Fundamentals \& Computational Aspects. Second ed., Tie-Line Publications, Holte, Denmark.

Moodley, K., Rarey, J., Ramjugernath, D., 2015. Application of the bio-inspired Krill Herd optimization technique to phase equilibrium calculations. Computers \& Chemical Engineering 74, 75-88.

NIST Chemistry WebBook, Accessed: 19.02.2016. NIST Standard Reference Database Number 69. http://webbook.nist.gov/cgi/cbook.cgi?ID= C106978\&Mask=4.

Peng, D.Y., Robinson, D.B., 1976. A new two-constant equation of state. Industrial \& Engineering Chemistry Fundamentals 15, 59-64.

Pérez Cisneros, E.S., Gani, R., Michelsen, M.L., 1997. Reactive separation systems-I. Computation of physical and chemical equilibrium. Chemical Engineering Science 52, 527-543. 
Phoenix, A.V., Heidemann, R.A., 1998. A non-ideal multiphase chemical equi-

Prigogine, I., Defay, R., 1947. On the number of independent constituents and the phase rule. The Journal of Chemical Physics 15, 614-615.

Rao, Y.K., 1985. Extended form of the Gibbs phase rule. Chemical Engineering Education 19, 46-49.

Saito, S., Michishita, T., Maeda, S., 1971. Separation of meta- and para-xylene mixture by distillation accompanied by chemical reactions. Journal of Chemical Engineering of Japan 4, 37-43.

Schott, G.L., 1964. Computation of restricted equilibria by general methods. The Journal of Chemical Physics 40, 2065-2066.

Smith, W.R., Missen, R.W., 1982. Chemical Reaction Equilibrium Analysis: Theory and Algorithms. Wiley, New York, United States of America.

Soave, G., 1972. Equilibrium constants from a modified Redlich-Kwong equation of state. Chemical Engineering Science 27, 1197-1203.

Stateva, R.P., Wakeham, W.A., 1997. Phase equilibrium calculations for chemically reacting systems. Industrial \& Engineering Chemistry Research 36, $5474-5482$.

Ung, S., Doherty, M.F., 1995a. Calculation of residue curve maps for mixtures with multiple equilibrium chemical reactions. Industrial \& Engineering Chemistry Research 34, 3195-3202.

Ung, S., Doherty, M.F., 1995b. Necessary and sufficient conditions for reactive azeotropes in multireaction mixtures. AIChE Journal 41, 2383-2392.

Ung, S., Doherty, M.F., 1995c. Synthesis of reactive distillation systems with multiple equilibrium chemical reactions. Industrial \& Engineering Chemistry Research 34, 2555-2565. 
Ung, S., Doherty, M.F., 1995d. Theory of phase equilibria in multireaction systems. Chemical Engineering Science 50, 3201-3216.

Ung, S., Doherty, M.F., 1995e. Vapor-liquid phase equilibrium in systems with multiple chemical reactions. Chemical Engineering Science 50, 23-48.

Wasylkiewicz, S.K., Ung, S., 2000. Global phase stability analysis for heterogeneous reactive mixtures and calculation of reactive liquid-liquid and vaporliquid-liquid equilibria. Fluid Phase Equilibria 175, 253-272.

White, III, C.W., Seider, W.D., 1981. Computation of phase and chemical equilibrium: Part IV. Approach to chemical equilibrium. AIChE Journal 27, $466-471$.

White, W.B., Johnson, S.M., Dantzig, G.B., 1958. Chemical equilibrium in complex mixtures. The Journal of Chemical Physics 28, 751-755.

Wilson, G.M., 1964. Vapor-liquid equilibrium. xi. a new expression for the excess free energy of mixing. Journal of the American Chemical Society 86, 127-130.

Xiao, W.d., Zhu, K.h., Yuan, W.k., Chien, H.H.y., 1989. An algorithm for simultaneous chemical and phase equilibrium calculation. AIChE Journal 35, $1813-1820$.

Zeleznik, F.J., Gordon, S., 1968. Calculation of complex chemical equilibria. Industrial \& Engineering Chemistry 60, 27-57. 


\section{Highlights}

- Equilibrium calculation of multiphase systems in presence of chemical reactions

- Robust variable initialization and stability analysis for equilibrium verification

- Successful calculations of two- and three-phase reaction systems

- Coupling with a second-order method can improve computation efficiency 